\title{
Circadian Modulation of Dopamine Levels and Dopaminergic Neuron Development Contributes to Attention Deficiency and Hyperactive Behavior
}

\author{
Jian Huang, ${ }^{1,2 *}$ Zhaomin Zhong, ${ }^{1,2 *}$ Mingyong Wang, ${ }^{1,2}$ Xifeng Chen, ${ }^{1,2}$ Yicheng Tan, ${ }^{1,2}$ Shuqing Zhang, ${ }^{1,2}$ Wei He, ${ }^{1,2}$ \\ Xiong He, ${ }^{1,2}$ Guodong Huang, ${ }^{1,2}$ Haiping Lu, ${ }^{3}$ Ping Wu, ${ }^{2}$ Yi Che, ${ }^{2}$ Yi-Lin Yan, ${ }^{1,4}{ }^{-}$John H. Postlethwait, ${ }^{4}$ Wenbiao Chen, ${ }^{1,5}$ \\ and $\odot$ Han Wang ${ }^{1,2}$ \\ ${ }^{1}$ Center for Circadian Clocks, ${ }^{2}$ School of Biology \& Basic Medical Sciences, Medical College, ${ }^{3}$ Department of Pediatrics and Child Health, Affiliated \\ Children's Hospital, Soochow University, Suzhou 215003, Jiangsu, China, ${ }^{4}$ Institute of Neuroscience, University of Oregon, Eugene, Oregon 97403, and \\ ${ }^{5}$ Department of Molecular Physiology and Biophysics, Vanderbilt University School of Medicine, Nashville, Tennessee 37232
}

Attention-deficit/hyperactivity disorder (ADHD) is one of the most prevalent psychiatric disorders in children and adults. While ADHD patients often display circadian abnormalities, the underlying mechanisms are unclear. Here we found that the zebrafish mutant for the circadian gene period1b (per1b) displays hyperactive, impulsive-like, and attention deficit-like behaviors and low levels of dopamine, reminiscent of human ADHD patients. We found that the circadian clock directly regulates dopamine-related genes monoamine oxidase and dopamine $\beta$ hydroxylase, and acts via genes important for the development or maintenance of dopaminergic neurons to regulate their number and organization in the ventral diencephalic posterior tuberculum. We then found that Per1 knock-out mice also display ADHD-like symptoms and reduced levels of dopamine, thereby showing highly conserved roles of the circadian clock in ADHD. Our studies demonstrate that disruption of a circadian clock gene elicits ADHD-like syndrome. The circadian model for attention deficiency and hyperactive behavior sheds light on ADHD pathogenesis and opens avenues for exploring novel targets for diagnosis and therapy for this common psychiatric disorder.

Key words: attention deficiency; circadian clock; dopamine; hyperactivity; per1b; zebrafish

\section{Introduction}

The circadian clock generates physiological and behavioral rhythms with a period of $\sim 24 \mathrm{~h}$ and plays a critical role in the sleep/wake cycle (Dijk and von Schantz, 2005). Circadian dysfunctions are thought to underlie the pathogenesis of many psychiatric disorders, including mania-like behavior and bipolar disorder (McClung, 2013). Attention-deficit/hyperactivity disorder (ADHD; Online Mendelian Inheritance in Man \#143465) is

\footnotetext{
Received June 9, 2014; revised Dec. 14, 2014; accepted Dec. 19, 2014.

Author contributions: J.H., Z.Z., and H.W. designed research;J.H., Z.Z., M.W., X.C., Y.T., S.Z., W.H., X.H., G.H., P.W., Y.C., Y.-L.Y., and H.W. performed research; W.C. contributed unpublished reagents/analytic tools; J.H., Z.Z., H.L., Y.-L.Y., J.H.P., and H.W. analyzed data; J.H., J.H.P., W.C., and H.W. wrote the paper.

This work was supported by the grants from the key grant program of the National Natural Science Foundation of China (NSFC; 31030062), the National Basic Research Program of China (973 Program; 2012CB947600), the general grant program of the NSFC (31000569 and 81070455), the National High Technology Research and Development Program of China (863 Program; 2011AA100402-2), the Jiangsu Distinguished Professorship Program (SR13400111), the Natural Science Foundation of Jiangsu Province (BK2012052), the Priority Academic Program Development of Jiangsu Higher Education Institutions (YX13400214), the High-Level Innovative Team of Jiangsu Province, and the National Institutes of Health Grant R01 0D011116. We thank Jia Hu for technical support, Heqi Lu (China Academy of Chinese Medical Sciences, Beijing) for helping measure DA concentrations, and Lisette Maddison and other members of our laboratories for helpful comments on the manuscript.

*J.H. and Z.Z. contributed equally to this work.

The authors declare no competing financial interests.

Correspondence should be addressed to Han Wang, Center for Circadian Clocks, Soochow University, 199 Renai, SIP, Suzhou 215123, Jiangsu, China. E-mail: han.wang88@gmail.com or wanghan@suda.edu.cn.

DOI:10.1523/JNEUROSCI.2551-14.2015

Copyright $\odot 2015$ the authors $\quad 0270-6474 / 15 / 352572-16 \$ 15.00 / 0$
}

one of the most prevalent psychiatric disorders in children and adults, affecting $\sim 3-5 \%$ of the population (Geissler and Lesch, 2011). ADHD is characterized clinically by hyperactivity, inattention, and impulsivity (Kendall et al., 2008), which significantly impair normal development of academic and social functions in children, and lead to secondary problems, such as delinquency and drug addiction, in adults (Rösler et al., 2004). One of the key clinical manifestations of ADHD patients is obvious hyperactivity that in turn results in sleep deprivation (Philipsen et al., 2006). Genome-wide association studies (GWAS) of ADHD patients have implicated genes involved in the endogenous circadian clock as risk factors for ADHD (Lasky-Su et al., 2008). Mice carrying the dominant negative Clock mutation show mania-like behavior, including hyperactivity, decreased sleep, lowered depression-like behavior, reduced anxiety, and an increased reward value in association with elevated dopaminergic activities in the central tegmental area (McClung et al., 2005; Roybal et al., 2007), while the circadian nuclear receptor Rev-erb $\alpha$ (Nr1d1) knock-out mice also display mania-like behavior, particularly hyperactivity and a central hyperdopaminergic state (Chung et al., 2014). In addition, dysrhythmias of melatonin production and altered expression of the circadian clock genes BMAL1 and PER2 appear to be associated with adult ADHD patients (Baird et al., 2012). The mechanisms by which the circadian clock impacts the pathogenesis of $\mathrm{ADHD}$, however, are far from certain. 
The zebrafish (Danio rerio) has been validated as a model for studying the genetic and developmental bases of behaviors (Lieschke and Currie, 2007), and has demonstrated its superiority for high-throughput drug screens for behavioral disorders in whole organisms (Rihel et al., 2010). Here, we set out to establish a zebrafish circadian model for attention deficiency and hyperactive behavior and to investigate the regulatory roles of the circadian clock in ADHD. We showed that zebrafish mutants for the circadian gene period $1 b$ (per1b, an ortholog of human PER1) display hyperactivity, impulsivity-like and inattention-like behaviors, and low levels of dopamine (DA), reminiscent of human ADHD patients. This zebrafish model with altered circadian rhythms demonstrates that ADHD behaviors in humans, rodents, and zebrafish are all associated with a dysfunctional DA system. Perlb acts via enzymes critical for DA metabolism to directly regulate the endogenous DA levels, and also through genes critical for development of dopaminergic neurons to possibly regulate their number and spatial organization. We also determined that Perl knock-out mice display ADHD-like symptoms, reduced levels of DA, and disregulation of DA-related genes, thereby suggesting that the regulatory roles of Perl in ADHD behaviors are conserved across vertebrates. The circadian models for attention deficiency and hyperactive behavior we describe provide insights into ADHD pathogenesis and should allow screens to identify novel targets for diagnosis and treatment for this common psychiatric disorder.

\section{Materials and Methods}

All procedures were approved by the Soochow University Animal Care and Use Committee and were in accordance with governmental regulations of China.

\section{Fish husbandry and embryo production}

Zebrafish, including a wild-type $\mathrm{AB}$ strain and per $1 b$ mutant lines, are raised at our fish facility according to standard protocols (Westerfield, 1993). Wild-type and mutant embryos were produced by pair matings, and then raised at $28.5^{\circ} \mathrm{C}$ in $\mathrm{E} 3$ embryo medium. To obtain larvae in the constant dark (DD) condition, embryos were first raised in the normal light/dark (LD, 14/10 h) condition for the first $3 \mathrm{~d}$ postfertilization (dpf) to activate and entrain the circadian system, and then transferred into the DD environment. For RNA isolation, embryos of different stages (every $4 \mathrm{~h}$ ) were collected and then stored at $-80^{\circ} \mathrm{C}$. For in situ hybridization and immunofluorescence staining, embryos or larvae were fixed in $4 \%$ paraformaldehyde (PFA) in PBS for $3 \mathrm{~h}$ at room temperature (RT) or overnight at $4^{\circ} \mathrm{C}$, then washed briefly with PBS, dehydrated, and stored in $100 \%$ methanol at $-20^{\circ} \mathrm{C}$ until use.

\section{Mutant generation and identification}

The zebrafish per $1 b$ mutant was generated through a retroviral insertion approach (Golling et al., 2002), whereby the retroviral sequence was inserted into the first intron of the per $1 b$ gene. To identify per $1 b$ mutants, two pairs of PCR primers were used. As shown in Figure $2 A$, primers $\mathrm{P} 1$ and P2 flanking the insertion site were used to amplify an expected $430 \mathrm{bp}$ PCR product specific to wild-type fish, while the mutant product would be $>6 \mathrm{~kb}$ too long to be amplified with this primer pair. Primer P3, located in genomic DNA to the left of the insertion site, and primer P4, which is inside the retroviral sequence, were used amplify an expected 734 bp PCR product specific to the insertional mutant. Thus, homozygous mutants would have a single $734 \mathrm{bp}$ band, wild-type fish a single 430 bp band, and heterozygous fish both bands (see Fig. 2B).

\section{Quantitative real-time PCR}

Using TRIzol reagent (Invitrogen), total RNAs were extracted from $\sim 50$ of the homozygous per $1 b$ or wild-type larvae every $4 \mathrm{~h}$ from 48 to $140 \mathrm{~h}$ postfertilization (hpf) for the LD condition and 96-140 hpf for the DD condition, and other groups of larvae of specified stages or treatments. After treating with DNase, $3 \mu \mathrm{g}$ of the purified total RNAs were reverse transcribed into cDNAs. Quantitative real-time PCR (qRT-PCR) was performed in an ABI StepOnePlus instrument with the SYBR green detection system (Invitrogen). PCR thermal profiles were 40 cycles with each cycle $10 \mathrm{~s}$ at $95^{\circ} \mathrm{C}$ and $30 \mathrm{~s}$ at $60^{\circ} \mathrm{C}$. Experiments were performed in triplicates, each with three different biological samples (nine replicates) for corresponding genotypes and developmental stages. All results were normalized to the expression level of the housekeeping gene $\beta$-actin. qRT-PCR results are shown as a relative expression level calculated using the $2^{-\Delta \Delta \mathrm{CT}}$ method (VanGuilder et al., 2008). $p$ values were calculated with one-way ANOVA test or Student's $t$ test.

\section{Luciferase reporter assays}

A 1698 bp $(-1489$ to $+209 \mathrm{bp})$ fragment of the zebrafish monoamine oxidase (mao, ENSDARG00000023712) promoter region containing 6 E' boxes (CANNTG) or a $1403 \mathrm{bp}(-1371$ to $+32 \mathrm{bp})$ fragment of zebrafish dopamine $\beta$ hydroxylase (dbh, ENSDARG00000069446) promoter region containing $7 \mathrm{E}$ ' boxes was amplified and cloned into the luciferase reporter-containing vector pGL4.17 (Promega), and named as pmaoPGL4 and pdbh-PGL4, respectively. Full-length cDNAs of zebrafish bmal1b (ENSDARG00000035732), clock1a (ENSDARG00000011703), clock2 (ENSDARG00000016536), perlb (ENSDARG00000016536), $c r y 1 a b$ (ENSDARG00000011583), and crylba (ENSDARG00000069074) genes (Kobayashi et al., 2000; Wang, 2008) were cloned into the pcDNA3.1 expression vector, respectively.

\section{Real-time bioluminescence monitoring in transgenic fish}

The two luciferase reporter constructs, pdbh-PGL4 and pmao-PGL4 (described above), were purified and linearized by NotI, and then microinjected into one-cell stage embryos for generating transgenic fish lines. Real-time bioluminescence of the $F_{1}$ transgenic larvae was monitored with a luminoskan ascent instrument (Thermo Fisher Scientific) using the dual-luciferase reporter assay system (Promega). The results were normalized by the CircWave (v3.3) software (Cho et al., 2012).

\section{Cell culture and cotransfections}

A mouse fibroblast cell line, NIH3T3, was used for cotransfection studies. Cotransfection and luciferase assays were performed according to the protocol described previously (Hampp et al., 2008).

\section{Antibodies and chromatin immunoprecipitation}

A peptide of 13 amino acids (PSSQLTQSPESDR) was selected from the Bmal $1 b$ protein sequence, synthesized, and used as an antigen to generate rabbit polyclonal antibody according to a standard protocol (Howard and Kaser, 2007). Peptides of 10 amino acids were selected. SEEPAHLKEQ was selected from the Period2 protein sequence. ALKAGESAEV was selected from the Perlb protein sequence. These were used to generate mouse monoclonal antibodies according to a standard protocol (Howard and Kaser, 2007). Bmal1b, Per2, and Per1b antibodies were effective in Western blotting experiments. Bmal1b and Per2 antibodies were used in chromatin immunoprecipitation (ChIP) assays, while the Perlb and Per2 antibodies were used for immunofluorescence staining experiments.

For ChIP assays, a group of 200 wild-type larvae at $5 \mathrm{dpf}$ was collected and cross-linked in 2\% formaldehyde at RT for $30 \mathrm{~min}$, then $1: 10 \mathrm{v} / \mathrm{v}$ of $1.25 \mathrm{M}$ glycine was added to stop cross-linking, followed by PBS washes $(3 \times$, each for $10 \mathrm{~min})$. The following procedures were performed according to the manufacturer's protocol (Millipore's ChIP assay kit). We used purified rabbit or mouse IgG (Invitrogen) as a negative control. ChIP PCRs were performed using primers flanking the E' box sites as well as primers not flanking the E' box sites in the $5^{\prime}$ promoter regions of $d b h$ and mao as controls.

\section{Whole-mount in situ hybridization}

Whole-mount in situ hybridization was conducted as described previously (Wang et al., 2007). Briefly, fixed larvae were incubated in 50\% formamide hybridization buffer with a DIG-labeled RNA probe at $70^{\circ} \mathrm{C}$ for 18-20 h. Both nitro blue tetrazolium and 5-bromo-4-chloro-3indolyl phosphate (Roche) were used for colorimetric detection. For each in situ hybridization experiment, 10-15 larvae were used. At least 
three independent in situ hybridization experiments were conducted for each gene with an antisense per $1 b$ probe.

\section{Western blotting analysis}

Zebrafish larvae at $5 \mathrm{dpf}$ were washed with fish water and homogenized in lysis buffer as described previously (Wang et al., 2011). Protein samples were separated with $8 \%$ SDS-PAGE and transferred to PVDF membranes. After blocking with $5 \%$ nonfat milk for $2 \mathrm{~h}$, PVDF membranes were incubated with primary antibody overnight at $4^{\circ} \mathrm{C}$. The next day, membranes were washed in TBST $(0.5 \%$ Tween 20$)$ three times, each for $10 \mathrm{~min}$, and then incubated for $4 \mathrm{~h}$ with anti-mouse or anti-rabbit HRP-conjugated secondary antibody (1:5000; Abcam) at $4^{\circ} \mathrm{C}$. After washing with TBST four times, 10 min each, membranes were detected by a chemoluminescent HRP substrate (Thermo Fisher Scientific).

\section{Immunofluorescence staining with tyrosine} hydroxylase antibody

A group of $125 \mathrm{dpf}$ zebrafish larvae were used to perform tyrosine hydroxylase (TH) immunofluorescence staining. Fixed larvae were placed in 30\% sucrose in PBS overnight and then transferred to Tissue-Tek O.C.T. and stored at $-26^{\circ} \mathrm{C}$. Sections with a thickness of $16 \mu \mathrm{m}$ were prepared using a cryostat (Leica CM1850). Immunofluorescence was performed as follows: slides with sections were washed with PBS ( $3 \times$, each for $10 \mathrm{~min}$ ), followed by PBST ( $3 \times$, each for $10 \mathrm{~min}$ ), and finally PBS plus $0.5 \%$ Triton X-100 ( $2 \times$, each for $5 \mathrm{~min})$. Sections then were blocked in $3 \%$ bovine serum albumin in PBS for $\geq 30$ min and incubated with TH primary antibody (mouse, 1:1000; Immunostar) overnight at $4^{\circ} \mathrm{C}$. The following day, sections were washed with PBS $(3 \times$, each for $10 \mathrm{~min})$ and PBS plus $0.1 \%$ Triton X-100 $(2 \times$, each for $5 \mathrm{~min}$ ). Sections were then incubated with secondary antibody (antimouse Alexa 488; A21202, Invitrogen) for $2 \mathrm{~h}$, followed by washing with PBS (6×, each for $10 \mathrm{~min}$ ). Slides were coverslipped using DAPI solution (Vector Lab, H1200). Images were taken using a Zeiss compound microscope (Axio Imager M2) with a digital camera and processed using Adobe Photoshop CS. A double-blind test was used to calculate the number of dopaminergic neurons in the ventral diencephalic posterior tuberculum (PT).

Immunostaining of the mouse brain was performed as described previously (Gong et al., 2011). Two-month-old mice were overdosed with pentobarbital and perfused with saline followed by $4 \%$ paraformaldehyde. The fixed brain was cryoprotected in $30 \%$ sucrose, and cut into 20 $\mu \mathrm{m}$ coronal sections on a cryostat (Leica CM1850). Sections were incubated with a mixture of two primary antibodies (mouse anti-TH, 1:1000; Immunostar; and rabbit anti-PER1, 1:600; Abcam, ab3443) overnight at $4^{\circ} \mathrm{C}$. After washing with PBS three times, sections were then incubated with a mixture of secondary antibodies (anti-mouse Cy3 conjugated, 1:1000; Invitrogen; and anti-rabbit Alexa 488 conjugated, 1:1000; Invitrogen) for $2 \mathrm{~h}$ at RT. After washing with PBS three times, sections were coverslipped with DAPI solution (Vector Lab, H1200).

\section{HPLC analysis}

Measurement of endogenous DA concentrations was performed at the Institute of Basic Chinese Medical Theory, China Academy of Chinese Medical Sciences. The protocol was performed as described previously (Lange et al., 2012). Brains of 12 adult fish (5-6-month-old) were dissected out at Zeitgeber time (ZT) 1 and ZT15 and fast frozen in liquid nitrogen, then stored at $-80^{\circ} \mathrm{C}$ until use. Approximately 100 larvae were fast frozen each at ZT2 (98 and $122 \mathrm{hpf}$ ) and ZT14 (110 and 134 hpf). Samples were stored at $-80^{\circ} \mathrm{C}$ until use. For HPLC analysis, $\sim 100$ zebrafish ( $\geq 50 \mathrm{mg}$ ) larvae or $50 \mathrm{mg}$ adult brains were homog- enized in $250 \mu \mathrm{l}$ of $0.1 \mathrm{M}$ acetic acid containing $10 \mu \mathrm{M}$ EDTA, ascorbic acid, and sodium metabisulfite. Samples were stored at $-80^{\circ} \mathrm{C}$ until analysis. Measurements of neurotransmitters, including DA, homovanillic acid (HVA), 3,4-dihydroxyphenylacetic acid (DOPAC), norepinephrine (NE), 5-hydroxyindoleacetic acid (5-HIAA), were performed on a Varian Polaris Programmable Binary Gradient HPLC System (Agilent Technologies). Reagents were purchased from Sigma-Aldrich. Calibration curves were obtained by injecting standard samples (DA, Sigma-Aldrich, H8502; HVA, Sigma-Aldrich, H1252; DOPAC, Sigma-Fluka, 11569; 5-HIAA, Sigma-Aldrich, H8876) of five different concentrations (5, 10, 20,40 , and $80 \mathrm{ng} / \mathrm{ml}$ ). Correlation coefficients were $>0.999$.

\section{Zebrafish behavioral analysis}

Long-term monitoring of locomotor activity. Locomotor activity analysis was performed as described previously with some modifications (Prober et al., 2006). On the fourth dpf, a single larva was placed in each of 72 wells of a 96 -well plate (36 wild types and 36 per $1 b$ mutants), which allowed simultaneous tracking of each larva. Locomotor activities of larvae were monitored for 4 consecutive days under the LD conditions using an automated video-tracking system (Videotrack, ViewPoint Life Sciences; or DanioVision Tracking System, Noldus Information Technology), and the movement of each larva was recorded and analyzed using Zebralab3.10 software (ViewPoint Life Sciences) or Ethovision 10.0 software (Noldus Information Technology). Ninety-six-well plates were placed inside the Zebrabox/DanioVision Observation Chamber where continuous infrared light was illuminated and white light was illuminated from 9:00 A.M. to 11:00 P.M. Instruments were placed in the chamber to maintain a constant temperature of $28.5^{\circ} \mathrm{C}$. The Videotrack quantization parameters were set as described previously (Appelbaum et al., 2010). The test was performed $\geq 3$ times. Data were further analyzed using custom R language and Visual Basic Macros for Microsoft Excel.

For the DD assay, live video tracking and analysis were conducted using Ethovision 10.0 software (Noldus Information Technology). The per $1 b$ mutant and wild-type embryos were kept under $\mathrm{LD}$ conditions for the first $3 \mathrm{~d}$ of development. On the fourth dpf, the mutant and wild-type larvae (48 each) were placed in a 96-well plate, which then was loaded inside the observation chamber of the DanioVision Tracking System (Noldus Information Technology). The temperature of the chamber was 
maintained at $28^{\circ} \mathrm{C}$ by a temperature control unit (Noldus Information Technology). The light was set at 300 lux during daytime of $4 \mathrm{dpf}, 0$ lux during nighttime of $4 \mathrm{dpf}$, and then at 30 lux for all subsequent days for the DD condition starting from 9:00 A.M. at 5 dpf. Activities were measured from days 5 to 10 postfertilization, and swimming distances of the larvae were recorded in 10 min time bins (Tovin et al., 2012; Ben-Moshe et al., 2014). Locomotor activities under DD conditions were repeated four times, and the data were calculated with Student's $t$ test using SPSS. Each value was shown as mean \pm SEM, considering $p<0.05$ as statistically significant. The period, amplitude, and phase were reanalyzed using a nonlinear least-squares minimization method (Pendergast et al., 2012; Liu et al., 2014). Activity levels that were above the $24 \mathrm{~h}$ average were plotted relative to the peak activity level in each actogram; activity levels below the $24 \mathrm{~h}$ average were set to zero (Hurd et al., 1998).

For the locomotor activity assay in adult fish, male or female adult fish were placed in $1 \mathrm{~L}$ tanks $(20 \times 8.5 \times 6 \mathrm{~cm})$ and transferred to the experiment room. All sides of the tank were covered by opaque tape to prevent external interference. After $1 \mathrm{~h}$ of acclimation, fish were placed in tanks containing system water to a depth of $6 \mathrm{~cm}$, and activities were measured. Using the same procedure for larval locomotor activity, swimming activities were monitored over $2 \mathrm{~h}$ by counting the swimming distance every $5 \mathrm{~min}$, for a total of 20 observation bins.

Active-avoidance conditioning paradigm for learning and memory ability analysis. The test was performed as described previously (Rawashdeh et al., 2007). Adult male zebrafish, 6-7 months of age, with an average length of $\sim 3 \mathrm{~cm}$, were trained on an active-avoidance conditioning (AAC) paradigm using a modified testing tank [dimensions, 20 (length) $\times 8.5$ (width) $\times 6 \mathrm{~cm}$ (height); water level, $5 \mathrm{~cm}]$. This testing tank had an opaque barrier with an underwater opening to allow passage. The barrier divided the tank into two compartments of equal size; the right compartment was covered with dark, opaque paper to form a dark area. An electrode was installed at the right end of this area (Fig. $1 A$ ). Animals had to cross the barrier to avoid electric shocks (50 mA; pulse duration, $10 \mathrm{~s}$; interpulse amplitude, $500 \mathrm{~ms}$; Fig. $1 \mathrm{~A}$ ). Before the test, the room light was turned off, with dim red light illuminating the left part of the testing tank. All the fish were placed individually in $1 \mathrm{~L}$ tanks and transferred to the experiment room for $\geq 1 \mathrm{~h}$ for acclimation. Before training began, fish were first put into the left part of the testing tank one by one, and nearly all the fish passed through the barrier to the dark part in $10 \mathrm{~s}$. Fish that did not go to the dark part in $10 \mathrm{~s}$ were excluded from the test. During the training period, the electric pulse was switched on as soon as the fish entered into the dark part (Fig. $1 A$, right compartment). Animals could learn to avoid the shock by swimming into the illuminated part within the first $10 \mathrm{~s}$ of each trial. Training was terminated once the animal was able to stay in the illuminated part for $>10 \mathrm{~s}$, and the time points of the electric pulse were recorded. The learning criterion was defined as staying correctly in the left, illuminated portion for $>10 \mathrm{~s}$ in 8 of 10 consecutive trials during the training period without returning to the dark compartment. Animals that did not achieve the criterion for learning ability within $30 \mathrm{~min}$ after the onset of training were excluded from the experiment. Testing at defined intervals $(24 \mathrm{~h})$ was used to estimate long-term memories. The test was performed at ZT8 (daytime) and ZT16 (nighttime).

Evaluation of retention. To quantitatively evaluate the ability of each learner to recall the AAC paradigm, a retention score (RS) was calculated using the following algorithm (Rawashdeh et al., 2007):

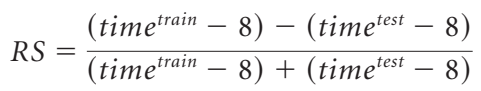

Training time required to reach the learning criterion in the test session was subtracted from the training time required to form the learning ability in the training session, divided by the training time in the testplus-training sessions.

Reward-mediated impulsivity evaluation. This test was performed as described previously (Parker et al., 2012). All behavioral testing took place in a custom-built tank. The tank was constructed from a translucent, nonreflective acrylic box [6 (height) $\times 8.5$ (width) $\times 20 \mathrm{~cm}$ (length); Fig. $1 B$ ], fitted with opaque barriers to form the response aper- tures and the food-magazine areas. The tank was filled with $3 \mathrm{~L}$ of system water. A high-speed camera (Videotrack, ViewPoint Life Sciences) was placed above the box to facilitate continuous real-time observation and recording of the fish in the test tank.

Before training, fish were not fed for $3 \mathrm{~d}$ and then were transferred into the testing tank without a barrier. The yellow and green LEDs were switched on to see whether the fish had color preference. We selected fish without color preference for further examination. During the training period, the barrier was added, and 5-10 live brine shrimps were injected near the green light $5 \mathrm{~s}$ after it was switched on to form a reward-stimulus system, then we put the fish into another part of the tank with the yellow LED switched on, but no brine shrimp were injected. Each fish was trained and tested separately. After consecutive daily trainings for a week, fish that had already formed a reward memory were selected to perform the test experiment. As a result, 36 fish for each genotype were selected.

During the test period, the barrier was taken away, and both LEDs were switched on. However, no brine shrimp were injected until 4 min later. Fish that entered the right region $(4 \times 4 \mathrm{~cm}$ region near the green light) and remained near the region for $10 \mathrm{~s}$ were regarded as "correct fish"; fish that never entered the region were considered as "incorrect fish"; and fish that entered the region but stayed $<5 \mathrm{~s}$ were identified as "omission fish."

Mirror-image attack test. The same tank used in the locomotor activity assay for adult fish was used for the mirror-image attack test, except that an $8 \times 8 \mathrm{~cm}$ mirror was placed outside one side of the tank. The numbers of times adult fish attacked the side with the mirror were recorded with the same automated video-tracking system mentioned above (see Movie 2).

Activities in light and dark as a measure of environmental sensitivity. The Zebrabox was illuminated with $90 \mathrm{~s}$ light/dark cycles (300 lux during illumination) and the locomotor activities of larvae were monitored as described above.

Drug treatments. All drug solutions were freshly prepared with system water on the day of the experiment. A group of 6-dpf-old larvae were incubated in drug solution with $5,10,15$, or $20 \mu \mathrm{M}$ of deprenyl (SigmaAldrich) or 5, 10, 15, 20, or $40 \mu \mathrm{M}$ of methylphenidate (MPH; SigmaAldrich), respectively, for $1 \mathrm{~h}$ to find an optimal concentration. The distance swum during a $5 \mathrm{~min}$ period was recorded for the different treatments as described above. Twenty-four wild-type larvae and 24 per $1 b$ mutant larvae were incubated in the optimal concentration in a 48-well plate for $1 \mathrm{~h}$, and the distance swum within $5 \mathrm{~min}$ was determined from the recording.

To determine the effect of Ritalin on mirror-attacking behavior, 8 -month-old mutant male and wild-type male fish were adapted to the testing room for $2 \mathrm{~d}$ without feeding, each housed in a $1.5 \mathrm{~L}$ tank containing $1 \mathrm{~L}$ system water. On the third day (1-5:30 P.M.), a mirror was placed outside one end of the tank and mirror-attacking behavior was monitored for $5 \mathrm{~min}$. On the fourth day, Ritalin was added to half of the fish tanks for each group to a final concentration of $100 \mu \mathrm{M}$, while the others were left alone. Mirror-attacking behaviors were monitored $1 \mathrm{~h}$ post-treatment. Total swimming distances and times of attacking the mirror side of the treated fish and untreated control fish were recorded within 5 min.

\section{Mouse behavior analysis}

The behavior analysis (open field, Morris water maze) for wild-type C57/B6 and Per1 (strain name: B6.129-Per1 ${ }^{\text {tm1Drw } / J, ~ h t t p: / / j a x m i c e . j a x . ~}$ org/strain/010491.html; Bae et al., 2001) knock-out mice was performed as described previously (Gunn et al., 2011).

\section{Results}

\section{Generation of a per $1 b$ mutant}

We generated a zebrafish mutant for the circadian clock gene per1b using a retroviral insertion approach (Golling et al., 2002), and found that the retroviral sequence was inserted into the first intron (Fig. $2 A, B$ ). A previous study showed that a viral insertion into the first intron before the start codon usually results in abnormal mRNA processing (Harbers et al., 1984). To test the hypothesis that the expression level of perlb mRNA is affected by 


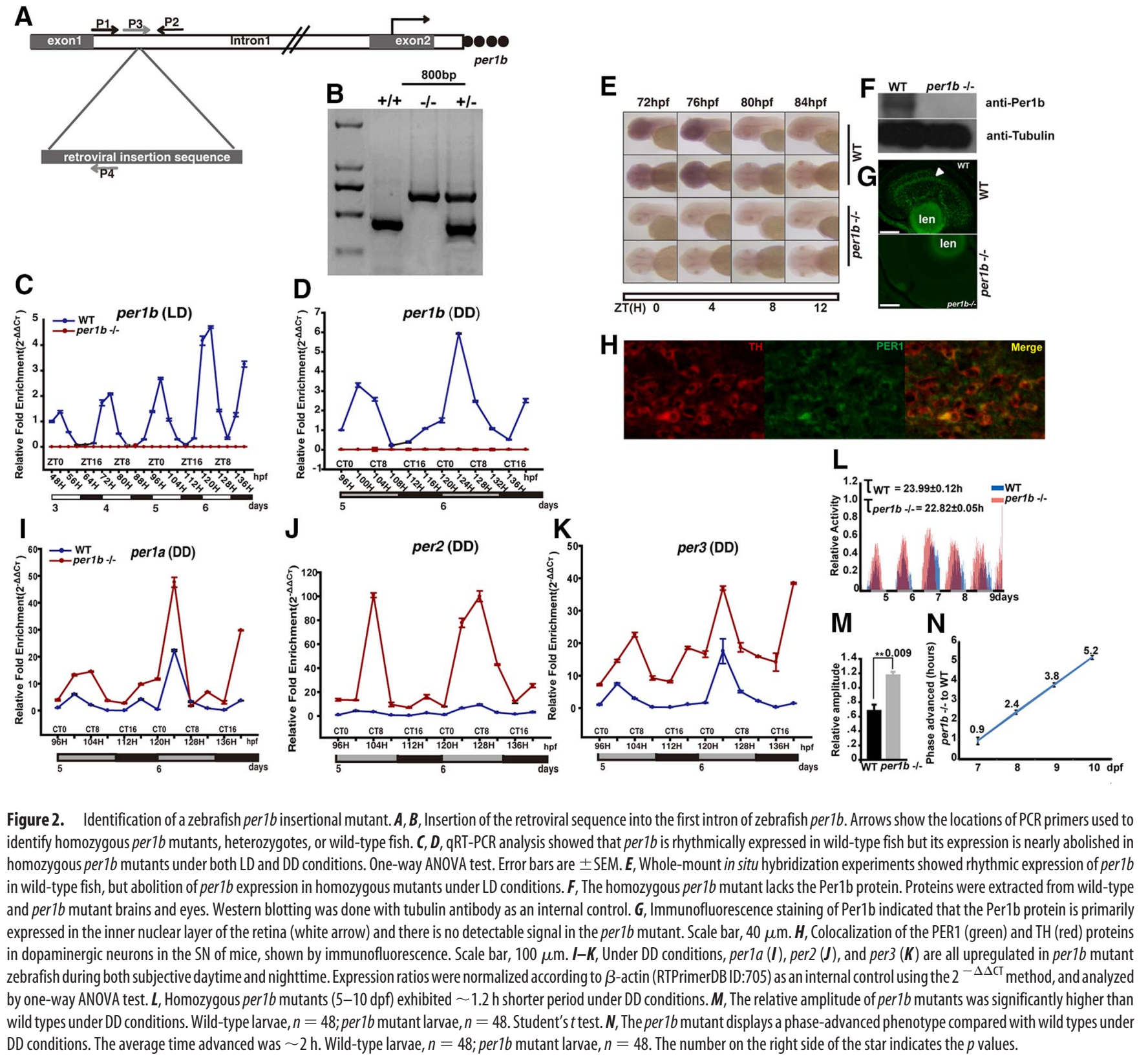

this type of retroviral integration, we performed qRT-PCR, semiquantitative RT-PCR, and whole-mount in situ hybridization. Results showed that wild types expressed per $1 b$ rhythmically under both LD and DD conditions, but that homozygous per $1 b$ retroviral insertion mutants showed only $\sim 10 \%$ of the wild-type per1b transcript levels (Fig. 2C-E). Western blotting with a Per1b monoclonal antibody showed a barely detectable signal in the per $1 b$ mutant but substantial signal from wild types (Fig. $2 F$ ), thus verifying the effect of the mutation on Perlb production. Immunofluorescence staining with the same antibody indicated that in wild types, the Per1b protein was expressed primarily in the eye, particularly in the inner nuclear layer of the retina, while in per $1 b$ mutants, little signal was detected (Fig. $2 G$ ). These results strongly indicate that the insertion mutant of per $1 b$ is likely a null-activity mutant. Furthermore, immunostaining demonstrated colocalization of the PER1 protein and TH in the dopaminergic neurons of the wild-type mouse brain substantia nigra (SN) region, which controls motivation and reward behaviors (Fig. $2 \mathrm{H}$ ), suggesting that Perl functions in dopomin- ergic neurons. We were unable to detect Perlb protein expression, however, in zebrafish dopaminergic neurons (data not shown), likely due to its low expression levels or a suboptimal antibody.

Zebrafish has four period genes: perla and perlb, which are both co-orthologs of mammalian Per1; and per 2 and per3, which are single orthologs of mammalian Per2 and Per3 (Wang, 2008). Under DD conditions, per $1 a$, per 2 , and per 3 were all significantly upregulated in per $1 b$ mutants during both the subjective daytime and the subjective nighttime (Fig. $2 I-K$ ), indicating that Per $1 b$ serves as a negative regulator of the three other period genes in the zebrafish circadian system. Intriguingly, under DD conditions, we found that the per $1 b$ mutant larvae displayed an $\sim 1.2 \mathrm{~h}$ shortened circadian period in comparison with wild types (Fig. $2 L$ ), consistent with an $\sim 1$ h shorter period found in Per 1 knock-out mice (Cermakian et al., 2001). The locomotor amplitude of the per1b mutant larvae was significantly higher than that of wildtype controls under DD conditions (Fig. 2M). Furthermore, the per $1 b$ mutant larvae showed a phase-advanced phenotype with 
A

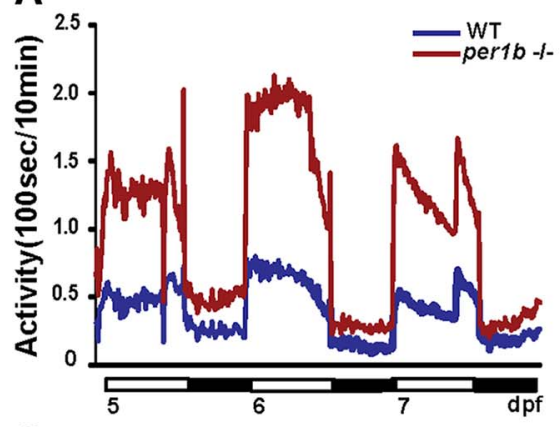

C

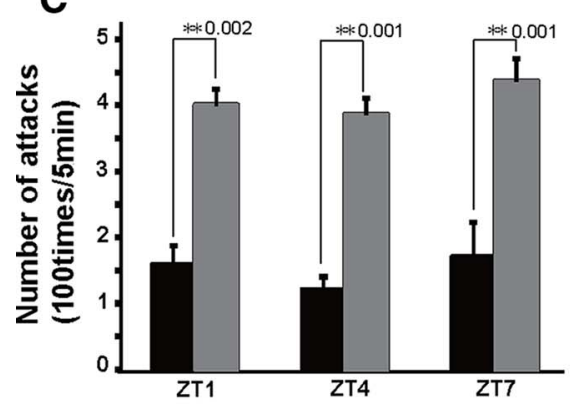

E

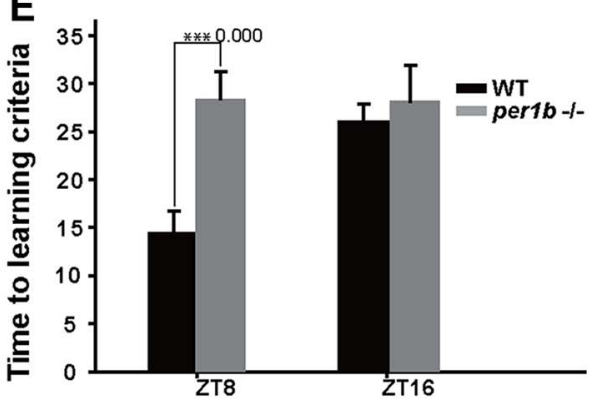

G

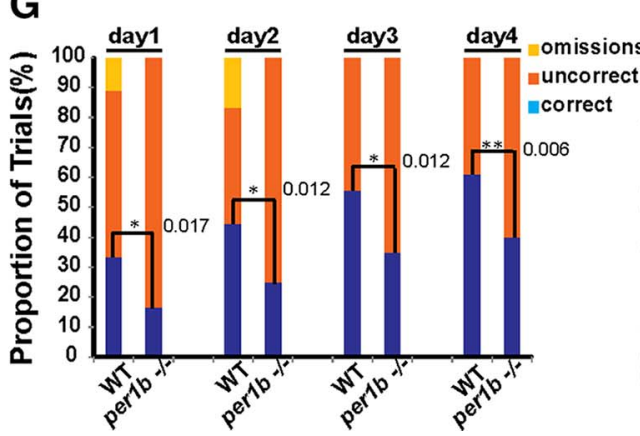

B

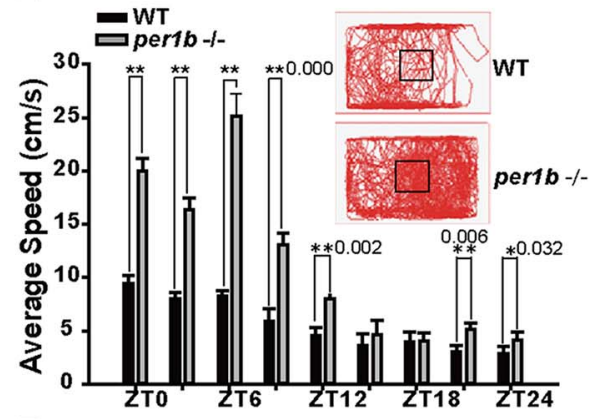

D
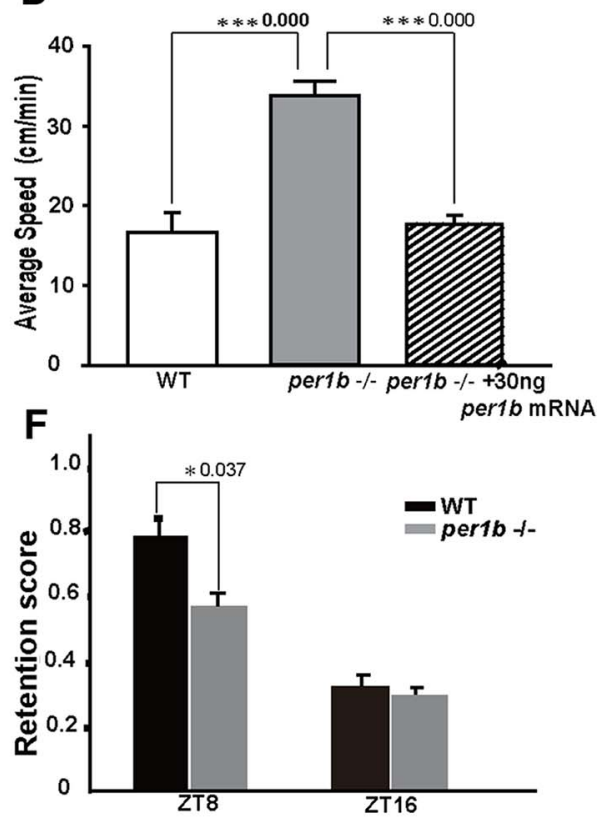

H

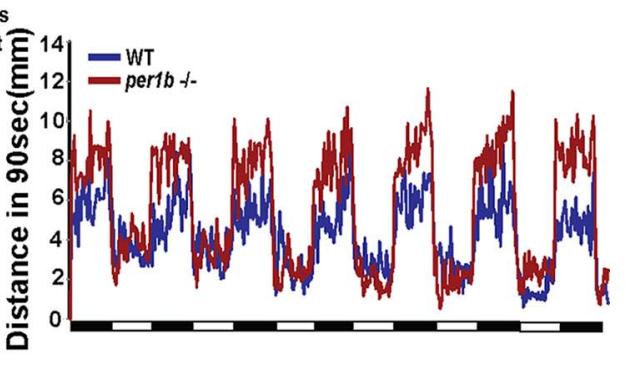

Figure 3. Homozygous per $1 b$ mutant zebrafish display ADHD-like behaviors. $A$, The per $1 b$ mutant larvae display hyperactive locomotor behaviors under LD conditions. Mean locomotion time was monitored in 5-7 dpf larvae. per $1 b$ mutant, $n=36$; wild type, $n=36$. Student's $t$ test. $\boldsymbol{B}$, The per $1 b$ mutant adults display hyperactive locomotor behaviors under $L D$ conditions. Mean average swimming velocities of per $1 b$ mutant and wild-type adult zebrafish at time-of-day points under $L D$ conditions (bars), and the accumulative total tracks of the per $1 b$ mutant and wild-type adult fish under LD conditions (rectangles). In addition to overall higher locomotor activities, per 16 mutant adults appear to exhibit relatively higher locomotor activities in the center of the tank than the wild-type fish (squares in the center), indicating a less centrophobic and anxious phenotypes in the per1b mutant adult fish. Error bars are \pm SEM. per $1 b$ mutant, $n=12 ;$ wild type, $n=12$. Student's $t$ test (Movie 1). C, Hyperactivity and impulsive-like behavior of the per $1 b$ mutant fish, shown by the mirror-image attack assay. per $1 b$ mutant, $n=18 ;$ wild type, $n=18$. Error bars are \pm SEM. Student's $t$ test (Movie 2). D, Hyperactivity of per $1 b$ mutant larvae can be rescued by microinjection of functional per $1 b$ mRNAs. Thirty nanograms of capped per $1 b$ mRNAs were injected into one-cell per $1 b$ mutant embryos and locomotor activities were monitored from 5 to $7 \mathrm{dpf}$. Error bars are \pm SEM. per $1 b$ mutant, $n=36$; wild type, $n=36$; per $1 b$-injected embryos, $n=36$. Student's $t$ test. $E$, Adult per1b mutant fish showed significant learning problems in the AAC paradigm. The per 16 mutant fish required more trials than wild types to learn to avoid electric shocks in the daytime (ZT8). $\boldsymbol{F}$, The performance of per $1 b$ mutant fish in the memory test was inferior to that of wild types during the daytime. Error bars are \pm SEM. per $1 b$ mutant, $n=12 ;$ wild type, $n=12$. Student's $t$ test. G, per $1 b$ mutant fish showed impulsivity-like symptoms determined by a food reward assay with the two-choice serial reaction-time task (see Materials and Methods). Correct (blue bars), incorrect (orange bars), and omission (yellow bars) results were marked with different colors. per $1 b$ mutant, $n=24$; wild type, $n=24$. $\boldsymbol{H}$, A short-period ( 90 s each) light-pulse test showed that per $1 b$ mutant larvae are more sensitive to rapid changes in the illumination environment than wild-type controls. A 90 s light/dark pulse cycle was programed to the testing chamber holding $6 \mathrm{dpf}$ larvae, and swimming distance during each cycle was monitored. per $1 b$ mutant, $n=36$; wild type, $n=36$. All the numbers on the right side of the star indicate the $p$ values. 


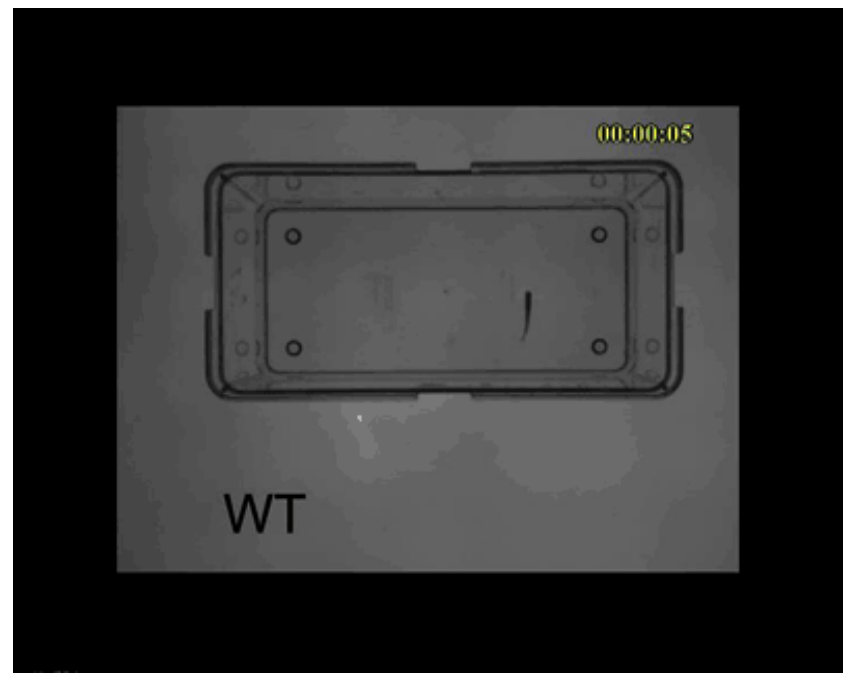

Movie 1. Hyperactivity of per1b adult mutant zebrafish. In comparison with wild types, per $1 b$ adult mutant zebrafish swam much faster and moved longer distances in the same time interval.

an average time of $2 \mathrm{~h}$ under DD conditions (Fig. $2 \mathrm{~N}$ ), similar to patients with familial advanced sleep phase syndrome due to a mutation in human PER2 (Toh et al., 2001). These results show that Perlb is essential for zebrafish circadian regulation.

\section{per $1 b$ mutant fish display hyperactive behavior}

We then further analyzed zebrafish locomotor activities under LD conditions and found that 5-7 dpf per $1 b$ mutant larvae were $\sim 3$ times more active than their wild-type counterparts during both daytime and nighttime (Fig. $3 A$ ). We also measured swimming velocities of adult fish. Similar to larvae, the mean swimming speed of per $1 b$ mutant adult fish was approximately twice that of wild-type fish during the daytime and nearly one and a half times the wild-type value during the nighttime (Fig. 3B; Movie 1). We conclude that per $1 b$ mutant larvae and adult fish both exhibit hyperactivity. In addition, we also observed that the per $1 b \mathrm{mu}-$ tants were less centrophobic than wild-type fish (Fig. $3 B$, rectangles). In other words, the per $1 b$ mutants displayed a dramatically increased exploratory behavior, implicating a reduced anxiety phenotype (Roybal et al., 2007).

We also used an image-attack assay (Bolyard and Rowland, 1996) to examine "perseveration," a key diagnostic criterion for hyperactivity in ADHD. High-speed camera monitoring showed that during the daytime (ZT1, ZT4, and ZT7), wild-type fish attacked their image intermittently in a 10 min interval. Wildtype fish would attack several times for a short period and then break off the attack, leave the mirror, and swim to other regions of the tank, and only resume attacking when they happened to see their image again. In contrast, per $1 b$ mutant fish attacked their mirror image nearly continuously in a $10 \mathrm{~min}$ period, failing to break off the attack as wild-type fish did. Thus the adult perlb mutant fish also displays perseveration-like behavior, shown by their persistently swimming toward the mirror side of the tank during the test (Fig. 3C; Movie 2).

To ensure that observed hyperactivity is caused by the per $1 b$ mutation rather than some other closely linked genetic aberration, we performed rescue experiments by microinjecting per $1 b$ capped mRNAs into one-cell zebrafish embryos. Results showed that hyperactivity of 5-7 dpf mutant larvae was rescued by per $1 b$

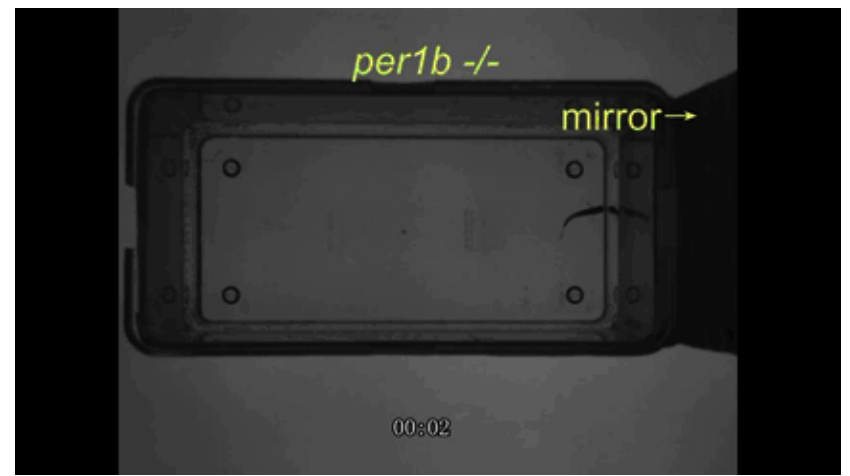

Movie 2. Impulsivity of per $1 b$ adult mutant zebrafish and its rescue by Ritalin treatment, determined by the mirror-image attack assay. Wild-type zebrafish attacked their mirror image, then broke off and attacked their mirror image again, while the per $1 b$ mutant zebrafish constantly attacked their mirror image, rarely breaking off (see text for discussion). The attacking times of per $1 b$ adult mutant fish are significantly reduced following $1 \mathrm{~h} 100 \mu \mathrm{m}$ Ritalin treatment.

functional mRNAs (Fig. 3D). We conclude that the viral insertion into the per $1 b$ gene is responsible for the behavioral abnormality.

\section{per $1 b$ mutant fish show learning-deficit and memory-deficit behaviors}

Next, we investigated the attention-deficit phenotype that also characterizes human ADHD patients. Recognizing that attention is particularly difficult to translate into defined behaviors in animal models and that distractibility and carelessness cannot easily be measured in such systems (Alsop, 2007), we focused on behaviors mimicking the forgetfulness and the trouble remembering obligations or appointments that are typical symptoms in both children and adult ADHD patients (Pastor et al., 2008). A well established methodology for examining learning and memory in adult fish is the AAC paradigm, in which one measures the ability of fish to learn and remember to avoid an electric shock by moving away from a naturally preferred dark area (but now an unsafe, shock-prone environment) into a naturally less favored light area (but now a safe, shock-free environment) of the tank (Fig. $1 A$; see Materials and Methods; Rawashdeh et al., 2007). We assessed this behavior in 2 consecutive days at two time-of-day points, ZT8 (daytime) and ZT16 (nighttime). During the training stage, at ZT8 in the daytime per $1 b$ mutants needed $\sim 28 \pm 2.8$ trials to learn to avoid the electric stimulus to criterion (see Materials and Methods), while wild-type controls needed only half as many trials ( $14 \pm 2.4$ trials). We conclude that per $1 b$ mutants are not able to learn as well as wild types. At ZT16 in the nighttime, however, wild-type controls and per $1 b$ mutants showed no significant difference, indicating that the per $1 b$ mutants have less ability to learn or focus on a special task, but only in the daytime (Fig. 3E).

During the test stage in the following day, we estimated the memory of fish using the RS (as described in Material and Methods), which reflects the ratio between training and testing performances. We observed that during the daytime at ZT8, per1b mutant fish showed a decreased ability to acquire and remember the AAC stimulus compared with wild-type fish, while no significant difference in memory acquisition or retention between wild-type controls and per $1 b$ mutants appeared during the nighttime at ZT16 (Fig. $3 F$ ). This result suggests that per $1 b$ mutant fish have a lower ability to form long-term memories than wild-type fish $(n=36, t$ test, $p<0.05)$. We conclude that per $1 b$ mutant fish show a clear deficit in learning and memory ability, which 
A

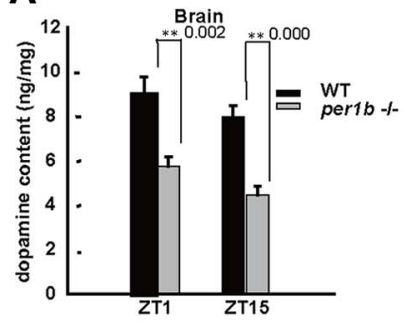

$E$

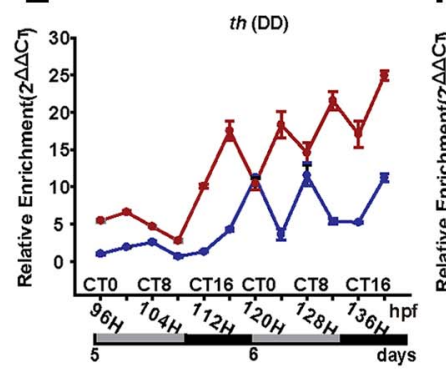

I

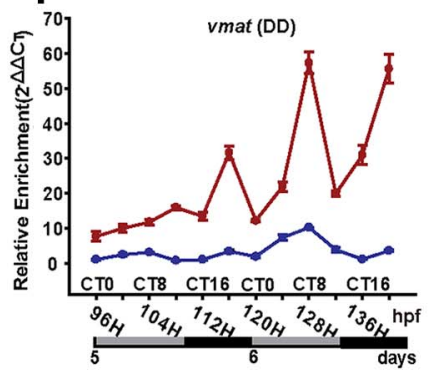

M

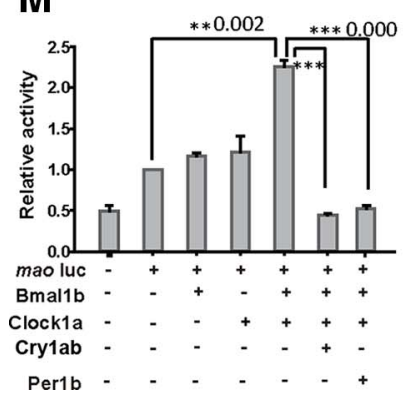

B

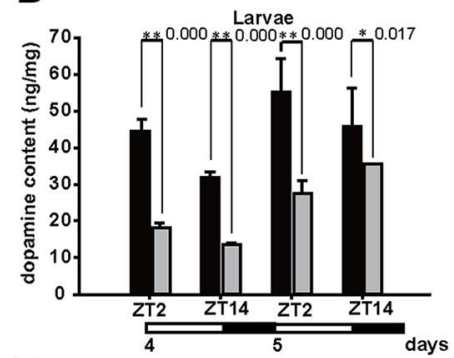

$\mathbf{F}$

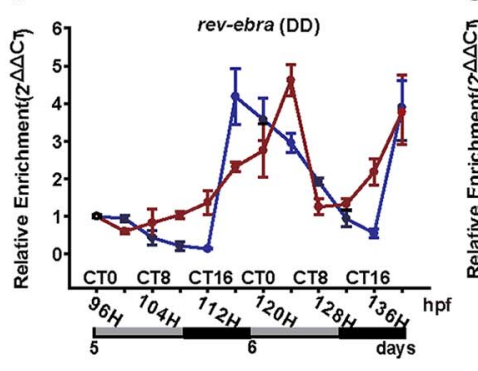

J

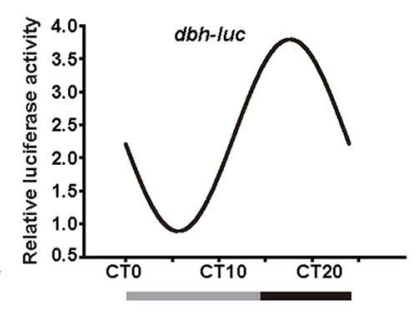

N
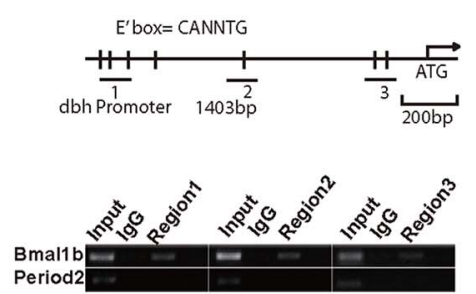

C

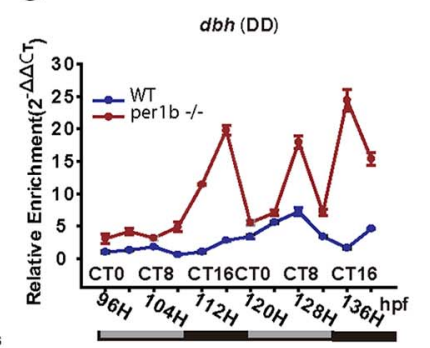

G

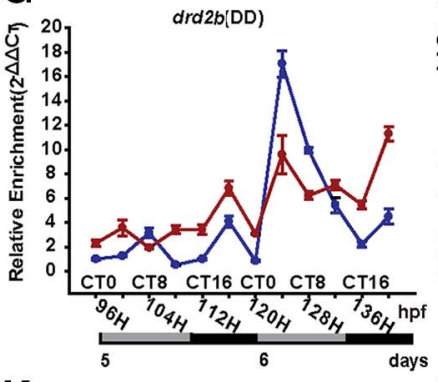

$\mathrm{K}$

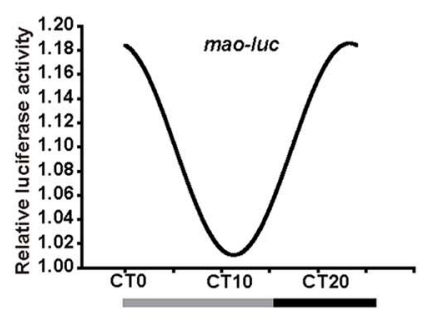

O
D

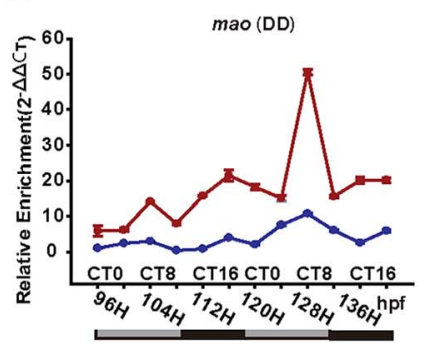

H

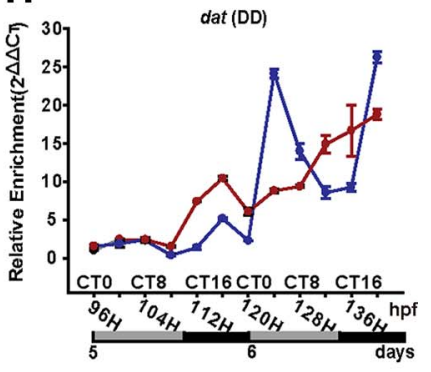

$\mathbf{L}$

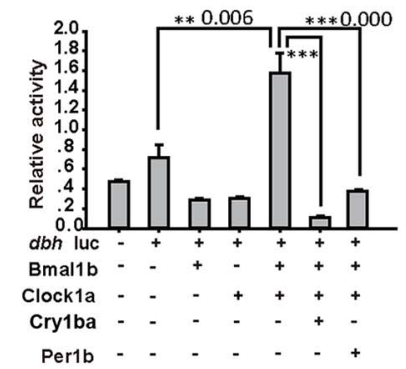

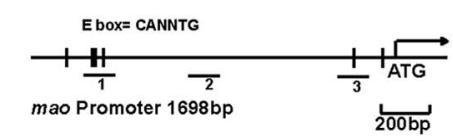

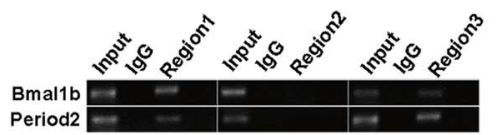

Figure 4. Circadian regulation of $d b h$ and mao and impaired DA signaling in per $1 b$ mutant zebrafish. $A, B$, Reduced DA levels in the per $1 b$ mutant adult brain $(\boldsymbol{A})$ and in larvae $(\boldsymbol{B})$, determined by HPLC. These experiments were performed in triplicate, with three biological samples for each experiment. Data were analyzed using a one-way ANOVA test. All error bars are \pm SEM. $C, D, q R T-P C R$ showed rhythmic expression of $d b h(\boldsymbol{C})$ and mao $(\boldsymbol{D})$ in wild-type larvae and their upregulation in per $1 b$ mutants under DD conditions. One-way ANOVA test. $\boldsymbol{E}$, Upregulation of th in the per1 $b$ mutant zebrafish. $\boldsymbol{F}$, rev-erb $\alpha(n r 1 d 1)$ shows a phase-delayed expression pattern in the per1b mutant fish under DD conditions. $\mathbf{G}-\mathbf{I}$, dopamine receptor D2 $b$ (drd2b; $\boldsymbol{G})$, dopamine transporter (dat; $\boldsymbol{H})$, and vesicular monoamine transporter $2($ vmat2; $I)$ in the per $1 b$ mutant zebrafish at most stages except for $124 \mathrm{hpf}$, when $\mathrm{drd} 2 \mathrm{l}$ and dat were dramatically increased, which could be a response to the initiation of foraging at that stage (see text for detail). $\boldsymbol{J}, \boldsymbol{K}, \mathrm{A}$ continuous luminescence monitor assay with transgenic analysis showed rhythmic expression of $d b h(\boldsymbol{J})$ and $\mathrm{mao}(\boldsymbol{K})$ in vivo. Data were normalized using CircleWave software. $\boldsymbol{L}, \boldsymbol{M}$, Cell transfection assays showed that $d b h$ is activated by Clock1a and Bmal1 b but repressed by Per1b or Cry 1 ba $(\boldsymbol{L})$, while mao is activated by Clock1a and Bmal $1 \mathrm{~b}$ but repressed by Per $1 \mathrm{~b}$ or Cry1ab $(\boldsymbol{M})$. Student's $t$ test. $\boldsymbol{N}, \mathbf{0}$, ChIP assays showed that Bmal $1 \mathrm{~b}$ and Period2 proteins bind $\mathrm{E}^{\prime}$ boxes in the $5^{\prime}$ regulatory region of $d b h(\boldsymbol{N})$ and $m a 0(\mathbf{0})$. The top of $\boldsymbol{N}$ and $\boldsymbol{O}$ show the three fragments from the $5^{\prime}$ regulatory region of $d b h$ for the ChIP assays. All the numbers on the right side of the star indicate the $p$ values.

mimics an important symptom in psychiatric disorders, especially ADHD. Despite the difficulty to directly characterize the attention behavior of fish, the deficit in learning and memory of the perlb mutant fish could be easily extrapolated to be hyperactivity-derived "inattention."

per $1 b$ mutant fish display impulsivity-like phenotype

Human ADHD patients show impulsivity and often have difficulty waiting for things they want. To investigate whether zebrafish per $1 b$ mutants show cognitive impulsivity, we performed a two-choice serial reaction-time task in adult fish as described previously (Parker et al., 2012), using a modified apparatus shown in Figure 1B. During 1-week-long consecutive daily training sessions, when a green light was accompanied by a food reward near the light, both the mutant and wild-type fish entered into the region near the green light within $1 \mathrm{~min}$ after it was switched on. In the following test phase, the green light was switched on but food was not added until a waiting period of 4 min. Results showed that during the 4 min waiting period, 35\% of wild-type fish maintained their attention to the task and stayed 
near the green light at the first day of test, and the proportion of wild types remaining near the green light in the waiting period increased with subsequent trials. In contrast, only $\sim 15 \%$ of per $1 b$ mutants stayed near the green light on the first test day, and although the proportion of fish remaining near the green light in the waiting period gradually increased in the following days as in wild types, this proportion was always significantly lower than that for wild types (Fig. 3G). Results are consistent with those displayed by rodent models of ADHD that were tested using a similar behavioral task (Bruno et al., 2007), indicating that per1b mutant fish display impulsivity. In addition, it is noteworthy that despite having learned the task, per $1 b$ mutants could not maintain their attention on the task at hand, as expected for an attention-deficit phenotype.

ADHD patients also tend to show impulsive behaviors, i.e., an inability to hold in check maladaptive behaviors. The persistent mirror-attacking behavior of the per $1 b$ mutant fish described above also can be construed as a trait similar to increased impulsivity or aggressiveness that makes the fish seemingly unable to break off ineffective behaviors (Fig. 3C; Movie 2).

Human patients who suffer from an impulsive control disorder frequently display an enhanced sense of arousal and are much more sensitive than other people to changes in the environment (Hollander and Stein, 2006). To test the response of perlb mutants to rapid change, we programed the ZebraLab aquarium system to deliver pulses of $90 \mathrm{~s}$ of light followed by $90 \mathrm{~s}$ of dark to the 96-well plate containing $6 \mathrm{dpf}$ larvae. We used the distance larvae swam in $90 \mathrm{~s}$ to estimate the locomotor response to the rapid light/dark changes. Results showed that per $1 b$ mutants are much more sensitive to the quick light/dark changes and are noticeably more agitated during the dark pulse than their wildtype controls (Fig. $3 H$ ), mimicking the agitated state of human ADHD patients. These results show that per $1 b$ mutant fish clearly display hyperactivity, forgetfulness, and impulsivity, all ADHDlike behaviors, described in the Diagnostic and Statistical Manual of Mental Disorders, Fifth Revised Edition (DSM-V), by the American Psychiatric Association.

\section{Disruption of the DA signaling pathway in per $1 b$ mutants}

To elucidate the physiological basis for ADHD-like behaviors in per1b mutant zebrafish, we examined DA levels because an abnormal DA system has been implicated in the etiology and pathogenesis of ADHD (Gong et al., 2011; Lange et al., 2012). Results showed that whole larval bodies and adult brains of per $1 b \mathrm{mu}-$ tants contained significantly lower levels of DA than wild-type controls (Fig. 4A, $B$; $t$ test, $p<0.05$ ) as assessed by HPLC. This result is consistent with findings for human ADHD patients and hypodopaminergic rodent models for ADHD (Gong et al., 2011). To investigate whether the circadian clock plays a role in regulating DA biosynthesis, metabolism, and signaling, we first examined expression of the mao gene, which encodes monoamine oxidases for decomposing DA into DOPAC. Results showed that mao is rhythmically expressed in wild-type larvae and upregu-
B C
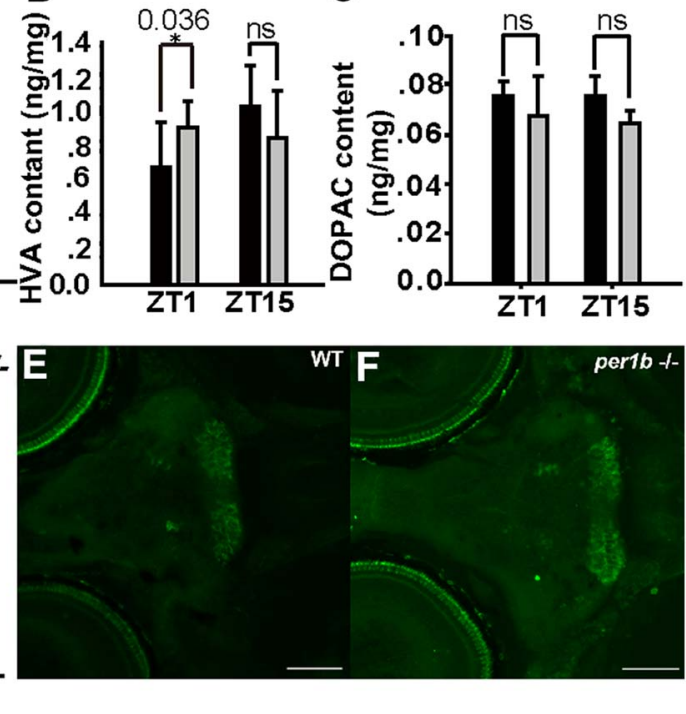

WT F

Figure 5. DA metabolites (HVA and DOPAC) and other catecholamines in per $7 b$ mutant and wild-type adult fish brains. $\boldsymbol{A}, \mathrm{NE}$ is is increased in the per 16 mutant brain only in the daytime (ZT) C C D No significant changes of the DA metabolite DOPAC (C) and 5-HIAA (the terminal metabolite of brain serotonin) were apparent in the per $1 b$ mutant brain compared with wild types. Numbers on the right side of the star indicate $p$ values. $\boldsymbol{E}, \boldsymbol{F}$, No significant changes of serotonin (5-hydroxytryptamine) neurons in the $6 \mathrm{dpf}$ per1b mutant brain $(\boldsymbol{F})$ compared with wild types $(\boldsymbol{E})$. Scale bar, $100 \mu \mathrm{m}$.

lated in per $1 b$ mutant larvae (Fig. $4 D$ ). DA can also be converted into NE, catalyzed by DA $\beta$ hydroxylase and we observed that $d b h$ is rhythmically expressed and upregulated in per $1 b \mathrm{mu}-$ tants (Fig. 4C). We also found that th (TH, ENSDARG00000030621) was upregulated in per1b mutants (Fig. $4 E$ ), which may be a compensatory response to the high expression levels of mao and $d b h$. A recent study showed that mouse Rev-erb $\alpha$ (Nr1d1, ENSDARG00000030621) inhibits Th expression (Chung et al., 2014). Here we examined zebrafish rev-erb $\alpha$ expression and found that it oscillates in wild types but exhibits an $\sim 8 \mathrm{~h}$ phase delay in mutants relative to wild types (Fig. $4 F$ ), likely resulting in a phase advance of th expression (Fig. 4E). In addition, dat (dopamine transporter, ENSDARG00000004219), $d r d 2 b$ (dopamine receptor $\mathrm{d} 2 \mathrm{~b}$, ENSDARG00000030621), and vmat (vesicular monoamine transporter, ENSDART00000025466) genes were all upregulated in per $1 b$ mutant larvae in all developmental stages except for 124 hpf, when dat and $d r d 2 b$ were dramatically increased in wild-type larvae (Fig. 4G-I). In Caenorhabditis elegans, DA is essential for sensing food and D1-like DA receptor DOP4 is responsible for this sensation (Ezcurra et al., 2011). Thus, it is likely that the increased expression of $d a t$ and $d r d 2 b$ at $124 \mathrm{hpf}$ may correspond to the initiation of foraging in zebrafish larvae at that stage. The underlying mechanism, however, requires further investigation. Previous studies showed that juvenile and adult ADHD patients have increased levels of striatal DA transporter (Dougherty et al., 1999; Cheon et al., 2003), which may result in reduced synaptic DA. The DA D2/3 receptor is markedly upregulated in adolescent ADHD patients (Lou et al., 2004). Thus, high expression of dat and $d r d 2 b$ may also contribute to the ADHD-like phenotype in zebrafish. The vesicular monoamine transporter is responsible for the uptake of cytosolic monoamines into synaptic vesicles, and the increase of DA release through amphetamine treatment results in a significantly lower level of vmat expression (Glaser and Gerhardt, 2012). Thus, the observed 

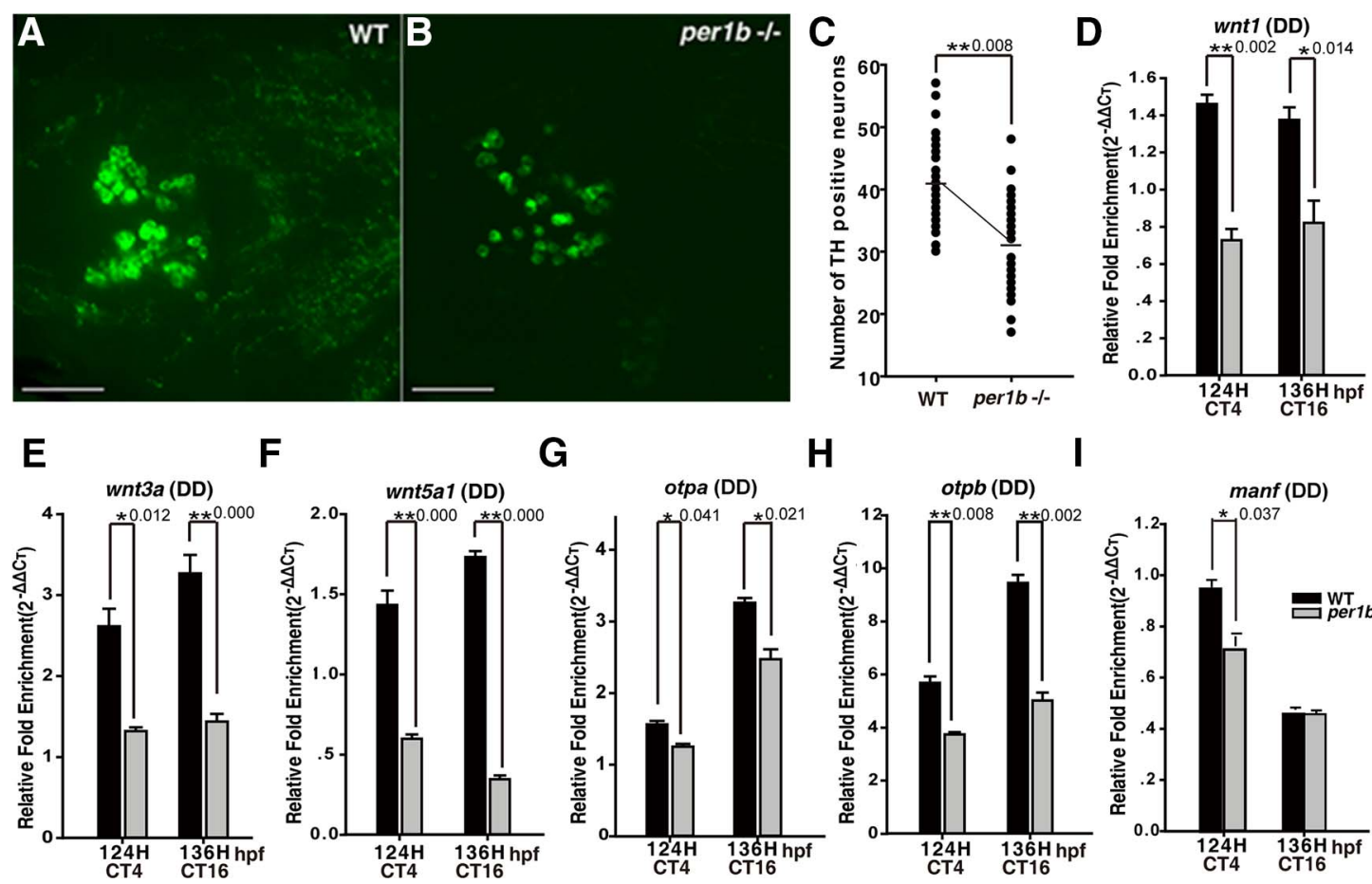

$\mathbf{F}$

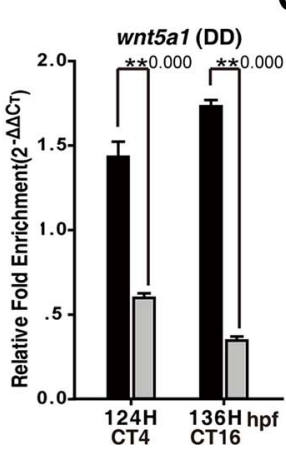

G

H
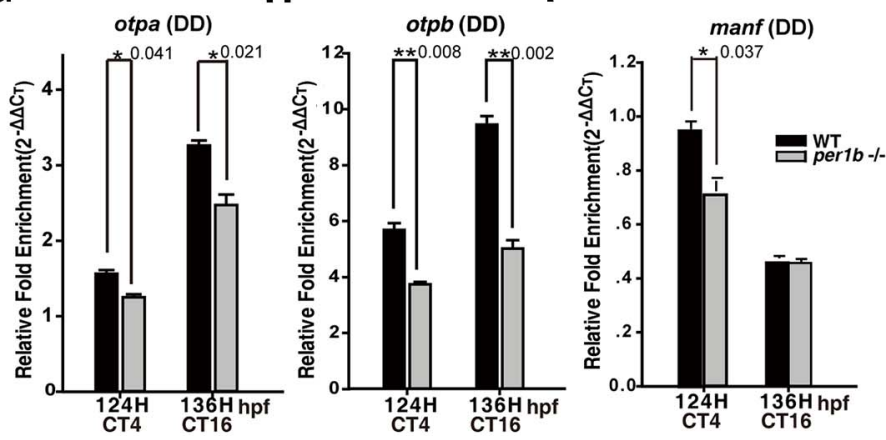

Figure 6. Partial loss and disorganization of dopaminergic neurons in the PT of the ventral diencephalon and downregulation of critical genes involved in specification, differentiation, and development or maintenance of dopaminergic neurons in per $1 b$ mutant zebrafish. $\boldsymbol{A}, \boldsymbol{B}$, Dopaminergic neurons in the PT of the ventral diencephalon of 5 dpf larvae (anterior to left), stained by anti-TH antibody. Scale bar, $50 \mu \mathrm{m}$. C, Numbers of positive TH neurons in per $1 b$ mutants and wild types, quantified with ImageJ cell counter function in double-blind scoring. Student's $t$ test. $D-I$, Downregulation of signaling proteins wnt $1(\boldsymbol{D})$, wnt3a $(\boldsymbol{E})$, and wnt5a $(\boldsymbol{F})$ and of transcription factors otpa $(\boldsymbol{G})$, otpb $(\boldsymbol{H})$, and manf $(\boldsymbol{I})$ involved in specification, differentiation, development, or maintenance of the dopaminergic neurons under DD conditions. Experiments were performed in triplicate, with three biological samples for each experiment. Data were analyzed using the Student's $t$ test. All error bars are \pm SEM. Numbers on the right side of the star indicate $p$ values.

upregulation of vmat also may be a compensatory response to the lower level of DA in per1b mutants.

The promoters of $d b h$ and mao both harbor a specific ciselement, the E-like box (CANNTG), as do other clock-controlled genes (Vallone et al., 2004), suggesting the hypothesis that $d b h$ and mao may be regulated by the circadian clock. To test this hypothesis, we placed $d b h$ and mao promoter fragments containing E-like boxes into luciferase-based reporter constructs, microinjected them into one-cell zebrafish embryos, and generated stable transgenic zebrafish lines. Real-time monitoring showed that $d b h$ and mao both oscillated in vivo (Fig. $4 J, K$ ). To see whether $d b h$ and mao are controlled by the circadian system in vitro, we also performed cell-transfection assays using mammalian NIH3T3 cells and these luciferase constructs. Activities of $d b h$ and mao promoters were significantly enhanced when cotransfected with Clock1a and Bmal1b (or Clock2 and Bmal1b for $m a o$ ), but cotransfection of expression vectors for the negative regulators, Crylba (or Crylab for mao) or Per1b, markedly reduced the promoter activities in NIH3T3 cells (Fig. $4 L, M$ ).

To investigate whether $d b h$ and mao genes are regulated by circadian clock genes in vivo, we performed ChIP experiments with a Bmal1b polyclonal antibody and a Period 2 monoclonal antibody. Results showed that Bmallb protein binds specifically to the E-like box elements of $d b h$ and mao promoter regions, which may activate expression of the two genes, while Per2 just binds to the E-like boxes of mao (Fig. 4N,O). These results unambiguously showed that both $d b h$ and mao are controlled directly by the circadian clock.

To determine whether the upregulation of $d b h$ and mao transcription in the per $1 b$ mutant leads to higher enzymatic activities, we measured enzymatic products. We observed significantly in- creased levels of NE (Fig. 5A) and HVA (Fig. 5B) in the perlb mutant, showing that upregulation of $d b h$ and mao mRNA (Fig. $4 C, D$ ) results in more DA $\beta$ hydroxylase and monoamine oxidase activity in per $1 b$ mutant fish. Because increased levels of NE were reported in both human ADHD patients and the mice ADHD model coloboma (Jones and Hess, 2003; Nestler et al., 2009), we think that elevated NE may also contribute to the behavioral phenotypes of per $1 b$ mutants; for instance, hypersensitive to rapid changes in light/dark periods and overagitation during the dark pulse (Fig. $3 G$ ), although the exact mechanism remains to be investigated. The levels, however, of both 5-HIAA (the final metabolite of brain serotonin; Fig. 5D) and serotonin neurons (Fig. 5E,F) are normal in perlb mutant fish, implying that serotonin (5-hydroxytryptamine) is not affected in per $1 b$ mutant fish.

\section{Altered dopaminergic neuron development in per1b mutants} In mammals, dopaminergic neurons in the ventral tegmental area of the midbrain and in the substantia nigra compacta (VTA/ $\mathrm{SNc}$ ) regulate complex behaviors, such as cognition, motivation, learning, and motor activity (Luo et al., 2011). In zebrafish, dopaminergic neurons in the PT of the ventral diencephalon, which project into the subpallium, have been likewise implicated in the regulation of complex behaviors (Tay et al., 2011). The seven distinct populations of dopaminergic neurons in the zebrafish PT integrate ascending and descending circuits for control of locomotion (Rink and Wullimann, 2002). Very little is known, however, concerning the possible effects of the development of these zebrafish dopaminergic neurons on the pathogenesis of ADHD (Lange et al., 2012). With double-blind scoring, we observed a significant decrease in the number of dopaminergic neurons in the per $1 b$ mutant ventral diencephalic PT at $5 \mathrm{dpf}$ in comparison 


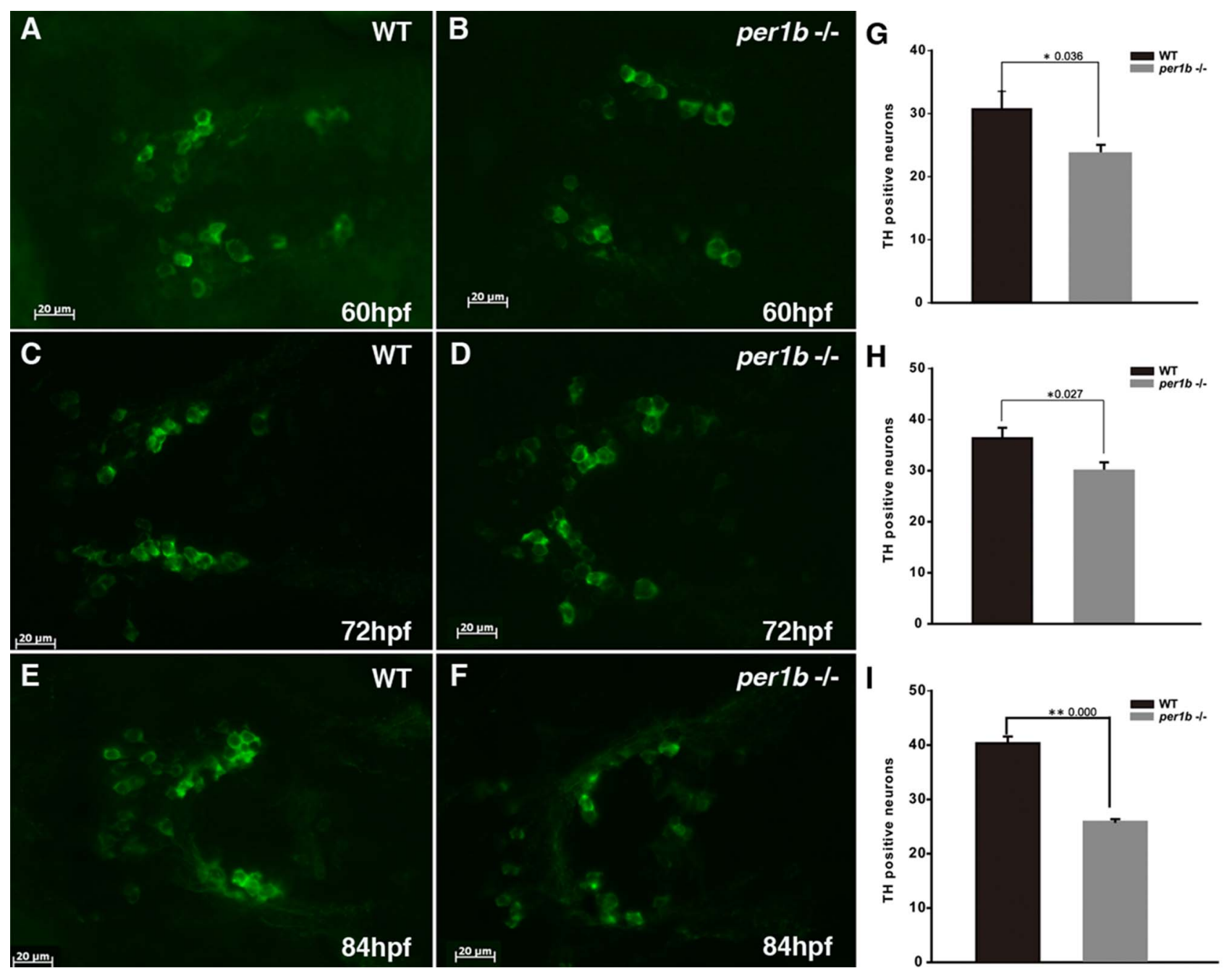

Figure 7. Continual loss of dopaminergic neurons in the PT of the ventral diencephalon from $60-84 \mathrm{hpf} \mathrm{in} \mathrm{per1b} \mathrm{mutant} \mathrm{zebrafish.} A, C, E$, Dopaminergic neurons in the wild-type PT. $B, D, F$, Dopaminergic neurons in the per $1 b$ mutant PT. Scale bar, $20 \mu \mathrm{m}$. G-I, The numbers of dopaminergic neurons in wild-type and per $1 b$ mutant larvae, determined with Image in a double-blind manner. $n=12$. Data were calculated in three independent experiments. Student's $t$ test was used in the statistical analysis. Error bars are \pm SEM. Numbers on the right side of the star indicate $p$ values.

with wild-type controls (Fig. 6A-C). Deficit of dopaminergic neurons occurred as early as $60-84 \mathrm{hpf}$ and continued thereafter in per $1 b$ mutants (Fig. 7). In addition, dopaminergic neurons in the perlb mutant PT appeared to be sparsely distributed and disorganized, rather than forming the regular seven populations as in the wild-type PT (Fig. 6A,B). This result shows that per $1 b$ activity is required for normal development or patterning of dopaminergic neurons.

To investigate possible mechanisms underlying the reduction and disorganization of dopaminergic neurons in the per $1 b$ mutant PT, we examined the expression of genes that play roles in specification, differentiation, and development or maintenance of dopaminergic neurons. In these experiments, only DD conditions were used to examine circadian regulation of these genes. Both orthopedia homeodomain protein (Otp) a (ENSDARG00000014201) and Otpb (ENSDARG00000058379) are required for the specification and development of dopaminergic neurons (Ryu et al., 2007); Wnt factors are critical for dopaminergic neuron differentiation and axonal extension (Castelo-Branco et al., 2003); and mesencephalic astrocyte-derived neurotrophic factor (Manf) plays a pivotal role in protecting dopaminergic neurons from neurotoxic damage (Chen et al., 2012). RT-PCR showed that wnt1 (ENSDARG00000055554), wnt3a (ENSDARG00000058822), wnt5a (ENSDARG00000014495; Fig. 6D-F), otpa, otpb (Fig. 6G,H), and mesencephalic astrocyte derived neurotrophic factor (manf, NM_001076629; Fig. 6I) are all significantly downregulated in per1b mutants under DD conditions. These results suggest that Per $1 \mathrm{~b}$ acts via Otp, Wnt signaling, and Manf to regulate specification, differentiation, development, and maintenance of dopaminergic neurons, but the mechanisms by which Perlb regulates these genes require further investigation. In addition, LATROPHILIN3 (LPHN3), which encodes a putative adhesion-G-protein-coupled receptor, has recently been implicated as an ADHD-susceptible gene (Arcos-Burgos et al., 2010). Knockdown of lphn3.1, a zebrafish ortholog of $L P H N 3$, results in reduction and misplacement of dopaminergic neurons in the ventral diencephalic PT and a hyperactive/impulsive phenotype (Lange et al., 2012). Consistent with those findings, we observed that lphn3.1 is significantly downregulated in per $1 b$ mutants (see Fig. $9 A$ ).

\section{Per1 knock-out mice display ADHD behaviors and reduced} levels of DA

To confirm the broad phylogenetic significance of our findings, we examined Perl knock-out mice (Bae et al., 2001; strain name:

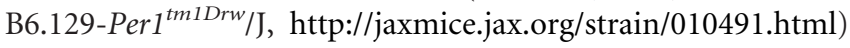
to see whether disruption of the circadian clock results in ADHD 
A
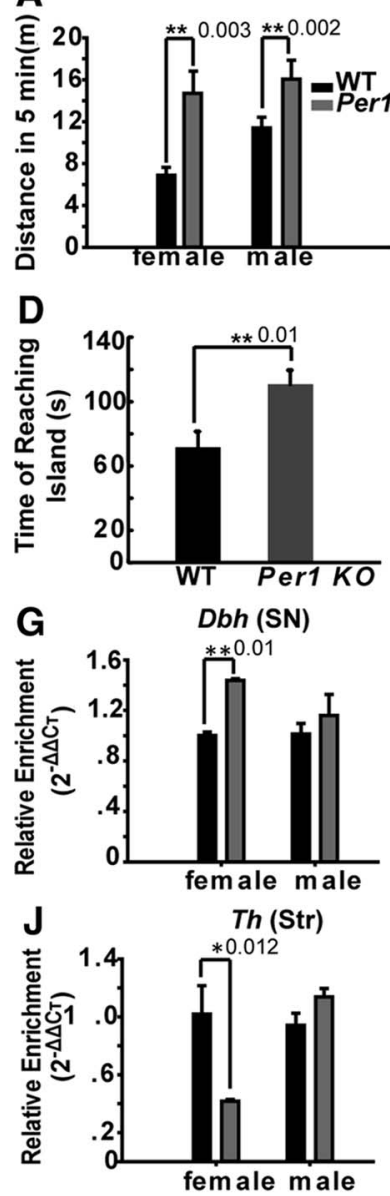

B
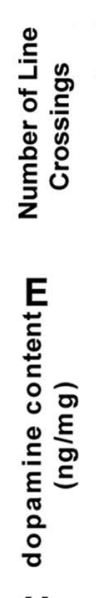

H

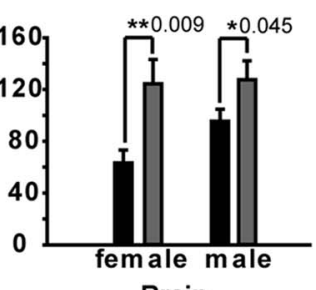
E $\quad .8 \quad \begin{gathered}\text { Brain } \\ * * 0.000\end{gathered}$
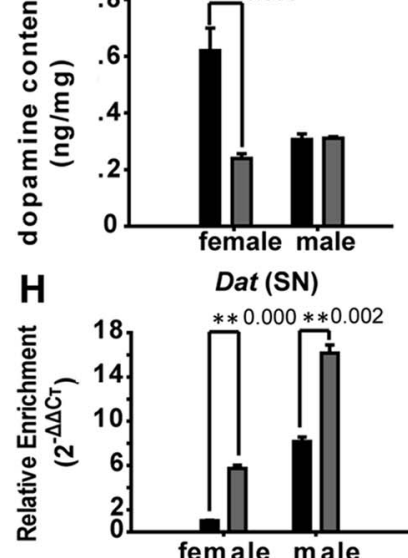

K

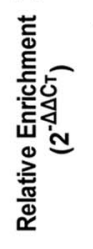

C
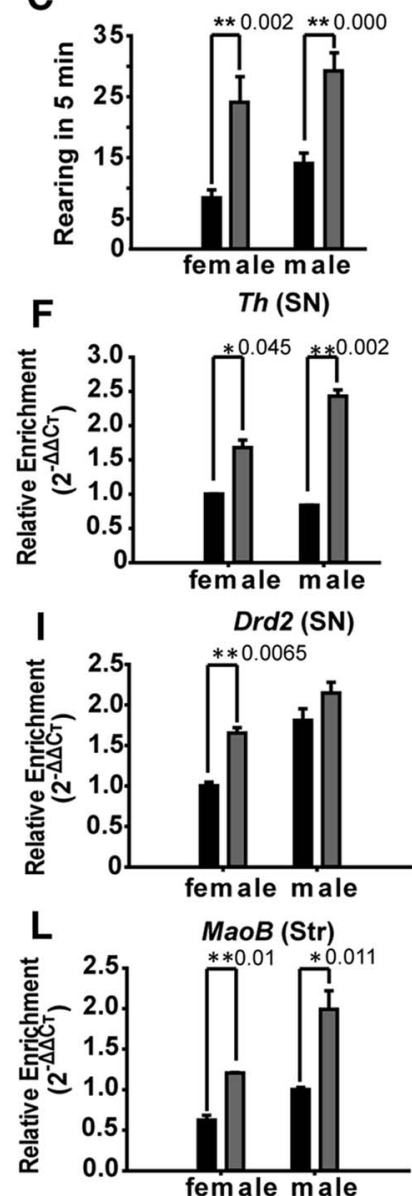

Figure 8. Per1 knock-out mice display ADHD-like symptoms, lower levels of DA, and abnormal expression of DA metabolism and signaling transduction pathway genes. $\boldsymbol{A}$, Distances that wild-type mice and Per 1 knock-out mice $(n=12$ each) traveled in $5 \mathrm{~min}$. $\boldsymbol{B}$, Lines crossed in an open-field test during 5 min. $\boldsymbol{C}$, The average rearing frequency during 5 min tests. Wild-type mice, $n=12$; Per 1 knock-out mice. $n=12$. Three sets of tests for each animal. $\boldsymbol{D}$, The learning and memory abilities of wild-type mice and Per $1 \mathrm{knock}$-out mice. $n=12$. Data were calculated for three independent experiments. $\boldsymbol{E}$, The DA level decreased in the brain of Per1 knock-out female mice compared with wild-type mice. Experiments were performed in triplicate, with three biological samples for each experiment. Data were analyzed using Student's $t$ test. All error bars are \pm SEM. $\boldsymbol{F}-\boldsymbol{I}, \operatorname{Th}(\boldsymbol{F}), \operatorname{Dbh}(\boldsymbol{G}), \operatorname{Dat}(\boldsymbol{H})$, and Drd2 $(\boldsymbol{I})$ are significantly upregulated in the SN of Per 1 knock-out mice midbrain. $\boldsymbol{J}$, The Th expression level is downregulated in the corpus striatum (Str) region of Per1 knock-out mice. $\boldsymbol{K}, \boldsymbol{L}, D b h(\boldsymbol{K})$ and $M a \circ B(\boldsymbol{L})$ are upregulated in the striatum region of Per1 knock-out mice. Numbers on the right side of the star indicate $p$ values.

symptoms in mammals as it does in fish. Using an open-field apparatus, we found that Per1 knock-out mice were hyperactive and impulsive (Fig. $8 A-C$ ) estimated by running distance and rearing frequency, respectively, and by the water maze assay, we observed that Per1 knock-out mice displayed impaired learning and memory (Fig. 8D). We also found that the DA level in the Per1 knock-out female mouse brain was significantly lower than in wild-type controls, as in zebrafish (Fig. 8E). We also examined the expression levels of genes involved in DA metabolism and signaling transduction pathways by qRT-PCR in the VTA/SNc. As in zebrafish per $1 b$ mutants, genes involved in DA metabolism and signal transduction were disregulated in Per1 knock-out mice either in the $\mathrm{SN}$ or corpus striatum (Fig. $8 F-L$ ). Although Per1 knock-out male mice also displayed ADHD-like symptoms and altered DA-related genes, we did not detect significantly lower levels of DA in their brains, which requires further investigation. Thus, it appears that circadian regulation of ADHD pathogenesis is highly conserved among vertebrate species.

Hyperactivity and impulsivity of per $1 b$ mutants can be rescued by ADHD drugs

If per $1 b$ mutant zebrafish mimic ADHD, then they should respond to drugs used to treat ADHD patients. ADHD thera- peutic agents include deprenyl (Selegiline), a monoamine oxidase inhibitor, and methylphenidate (MPH, or Ritalin), an amphetamine-like compound that represses DA transporter. These drugs can temporally restore extracellular DA levels and thus relieve some ADHD symptoms, including hyperactivity (Zhu et al., 2014). We treated larvae with different concentrations of MPH or deprenyl by directly adding the drug to the water for $1 \mathrm{~h}$ and then measured mean swimming speed. We found that treatment with 5 $\mu \mathrm{M}$ of either MPH or deprenyl was sufficient to reduce the hyperactivity of per $1 b$ mutant larvae to approximately the activity level of wild-type controls, but that the same concentration of these drugs exerted no effect on locomotion of wild-type larvae (Fig. 9B,C). These results show that, as in human ADHD patients and rodent models of ADHD, treatment with Ritalin or Selegiline was sufficient to rescue hyperactivity in the per $1 b$ mutant larvae.

Because these drugs also help reduce impulsive actions and improve attention and cognition (Geissler and Lesch, 2011), we tested whether Ritalin can rescue the mirror-attacking phenotype of per $1 b$ mutant zebrafish. The persistent mirrorattacking behavior of per $1 b$ mutant adult fish was significantly reversed with a $1 \mathrm{~h}$ treatment of $100 \mu \mathrm{M}$ Ritalin (Fig. 9D; Movie 2). While we regard the mirror-attacking phenotype of per $1 b$ mutant fish as impulsive or aggressive behavior, it also 
A

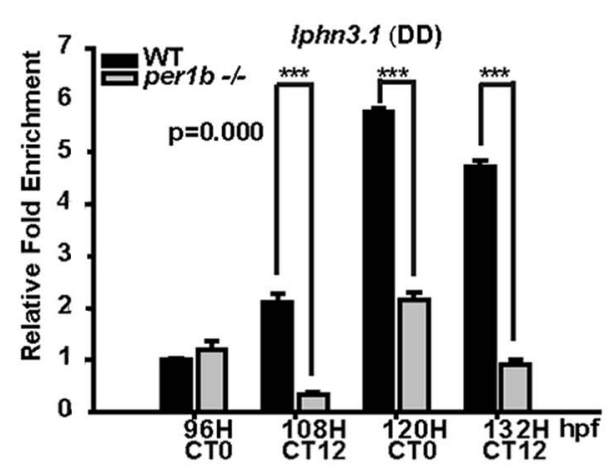

C

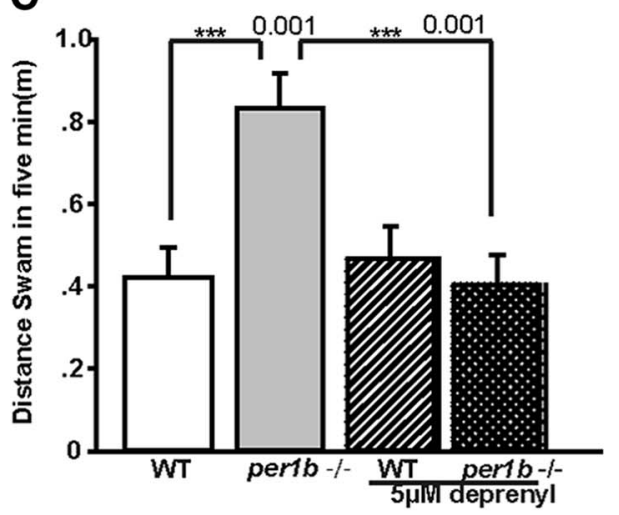

E

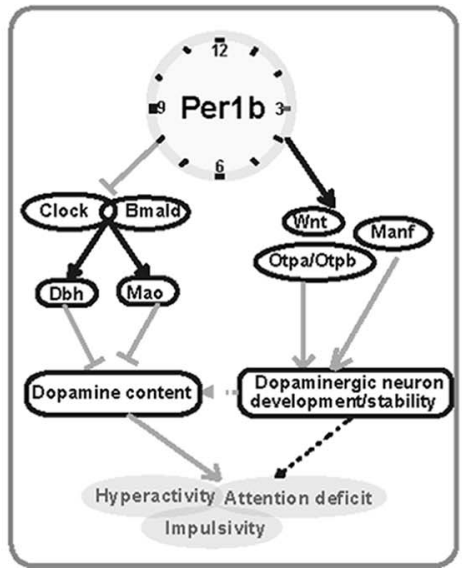

B

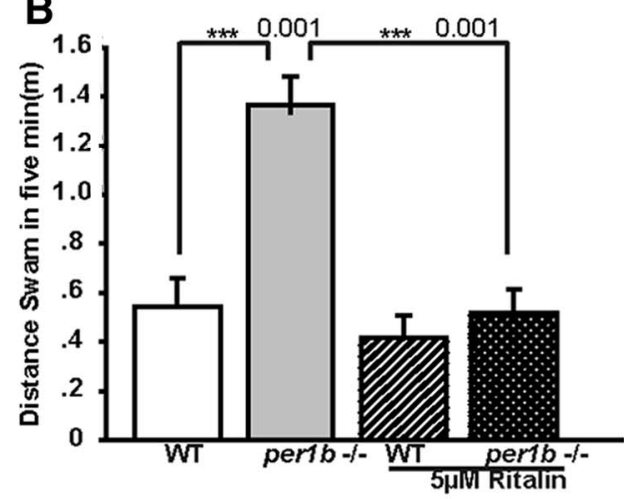

D

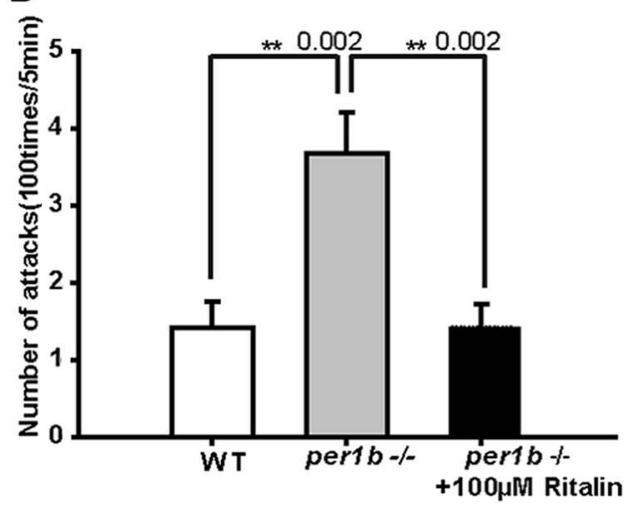

Figure 9. Rescue experiments with ADHD treatment drugs MPH (Ritalin) and deprenyl (Selegiline) and a model for the regulatory roles of Per1b in ADHD. A, downregulation of the ADHDsusceptible gene Iphn3.1 (latrophilin 3.1) in per1b mutant zebrafish as shown by qRT-PCR. Error bars are \pm SEM. Student's $t$ test. $\boldsymbol{B}$, Rescue of per $1 b$ mutant hyperactivity by MPH treatment. Shown are swimming distances in 5 min intervals of $6 \mathrm{dpf} \mathrm{MPH-treated} \mathrm{and} \mathrm{control} \mathrm{larvae.} \mathrm{Wild-type}(n=18)$ and per $1 b$ mutant larvae $(n=18)$ before and after a $1 \mathrm{~h}$ treatment with $5 \mu \mathrm{M} \mathrm{MPH}$. The same larvae were analyzed before and after treatment. Student's $t$ test. C, Rescue of per $1 b$ mutant hyperactivity by deprenyl treatment. Shown are swimming distances in 5 min intervals of 6 dpf deprenyl-treated and control larvae. Wild-type $(n=18)$ and per $1 b$ mutant larvae $(n=18)$ before and after a $1 \mathrm{~h}$ treatment with $5 \mu \mathrm{m}$ deprenyl. The same larvae were analyzed before and after treatment. Student's $t$ test. $\boldsymbol{D}$, Rescue of per $1 b$ mutant impulsivity by MPH treatment. Shown are mirror-attack times in 5 min intervals of 3-month-old MPH-treated and control adult fish. Wild-type $(n=18)$ and per $1 b$ mutant fish $(n=18)$ before and after a $1 \mathrm{~h}$ treatment with $100 \mu \mathrm{M}$ MPH. The same fish were analyzed before and after treatment. Student's $t$ test (Movie 2$)$. $\boldsymbol{E}$, A model for the role of Per $1 \mathrm{~b}$ in $\mathrm{ADHD}$ through regulation of $\mathrm{DA}$ metabolism/degradation and dopaminergic neuron development and maintenance. The circadian clock regulates mao and dbh. Additionally, Per $1 \mathrm{~b}$ itself or the circadian clock system directly or indirectly acts via otpa, otpb, wnts, and manf, which are critical for specification, differentiation, development, and maintenance of dopaminergic neurons. The purpose of this action is probably regulate the number and organization of dopaminergic neurons in the ventral diencephalic PT. Numbers on the right side of the star indicate $p$ values.

mimics hyperactivity or perseveration of ADHD $(D S M-V)$. The observation that ADHD drugs can rescue both the hyperactivity and mirror-attacking phenotypes of perlb mutant fish supports our notion that this circadian mutant zebrafish is an invaluable tool for investigation of ADHD pathogenesis and serves to identify other drugs that might be useful for human patients.

\section{Discussion}

We have established a mutant with altered circadian rhythms that clearly displays hyperactive, defective learning and memory, and impulsivity-like symptoms. These findings lead us to propose that these phenotypes mimic the symptoms of human ADHD patients and that perlb mutant fish should be used for studying 
Table 1. Comparisons between human ADHD and some animal models for ADHD

\begin{tabular}{|c|c|c|c|c|c|c|c|c|}
\hline \multirow[b]{2}{*}{ Subject } & \multirow[b]{2}{*}{ Modification } & \multirow[b]{2}{*}{ Hyperactivity } & \multicolumn{2}{|c|}{ Rescued by therapeutic treatments } & \multirow[b]{2}{*}{ Impulsivity } & \multirow[b]{2}{*}{ Inattentiveness } & \multirow[b]{2}{*}{ DA level } & \multirow{2}{*}{$\begin{array}{l}\text { Disrupted } \\
\text { dopaminergic } \\
\text { neuron }\end{array}$} \\
\hline & & & Ritalin (MPD) & $\begin{array}{l}\text { Selegiline } \\
\text { (deprenyl) }\end{array}$ & & & & \\
\hline ADHD (human) & & $\begin{array}{l}\text { Yes (Geissler and } \\
\text { Lesch, 2011) }\end{array}$ & $\begin{array}{l}\text { Yes (Geissler and } \\
\text { Lesch, 2011) }\end{array}$ & $\begin{array}{l}\text { Yes (Akhondzadeh } \\
\text { et al., 2003) }\end{array}$ & $\begin{array}{c}\text { Yes (Pastor } \\
\text { et al., } \\
2008 \text { ) }\end{array}$ & $\begin{array}{c}\text { Yes (Pastor et } \\
\text { al., 2008) }\end{array}$ & Decrease & Not determined \\
\hline $\begin{array}{c}\text { Guanylyl cyclase-c (Gc-c) } \\
\text { knock-out (mouse) }\end{array}$ & $\begin{array}{l}\text { Knock-out of the Gc-c } \\
\text { gene }\end{array}$ & $\begin{array}{l}\text { Yes (Gong et al., } \\
\text { 2011) }\end{array}$ & $\begin{array}{l}\text { Yes (Gong et al., } \\
\text { 2011) }\end{array}$ & Not determined & $\begin{array}{l}\text { Yes (Gong } \\
\text { et al., } \\
\text { 2011) }\end{array}$ & $\begin{array}{r}\text { Yes (Gong et } \\
\text { al., 2011) }\end{array}$ & $\begin{array}{l}\text { Decrease (Gong } \\
\text { et al., 2011) }\end{array}$ & Not determined \\
\hline $\begin{array}{l}\text { Coloboma mutant } \\
\text { (mouse) }\end{array}$ & $\begin{array}{l}\text { Mutation on the SNAP-25 } \\
\text { gene }\end{array}$ & $\begin{array}{l}\text { Yes (Hess et al., } \\
\text { 1992) }\end{array}$ & $\begin{array}{l}\text { No (Hess et al., } \\
\text { 1996) }\end{array}$ & Not determined & $\begin{array}{c}\text { Yes (Bruno } \\
\text { et al., } \\
2007 \text { ) }\end{array}$ & Not determined & Not determined & Not determined \\
\hline $\begin{array}{l}\text { per1b mutant } \\
\text { (zebrafish) }\end{array}$ & $\begin{array}{l}\text { Retrovirus insertion in the } \\
\text { per1b gene }\end{array}$ & Yes & Yes & Yes & Yes & Yes & Decrease & Yes \\
\hline Per1 knock-out (mouse) & $\begin{array}{l}\text { Knock-out of the Per1 } \\
\text { gene }\end{array}$ & Yes & Not determined & Not determined & Yes & Yes & Decrease & Not determined \\
\hline
\end{tabular}

the mechanistic basis of ADHD (Fig. 9E; Table 1). Like human ADHD patients and rodent models of ADHD (Gong et al., 2011), homozygous perlb mutant zebrafish display hyperactivity, impulsiveness, and impairment of sustained attention (Fig. $3 A-H$ ); contain low levels of DA; and respond to the ADHD treatment drugs Ritalin (MPH) and Selegiline (deprenyl) (Fig. 9B-D; Table $1)$. These results demonstrate not only that perlb mutant zebrafish meet the criteria of face validity, construct validity, and predictive validity of ADHD models, but also that a dysfunctional DA system is a highly conserved hallmark of ADHD in human, rodents, and zebrafish (Gong et al., 2011; Baird et al., 2012; Lange et al., 2012; Table 1). Furthermore, we also observed that Per1 knock-out mice display ADHD-like symptoms, suggesting that circadian roles in ADHD pathogenesis are highly conserved (Fig. $8 E)$. Although we were unable to detect any protein signal in the DA neurons, likely due to the suboptimal zebrafish Per1b antibody, the RNA in situ hybridization results showed that per $1 b$ is ubiquitously expressed in the brain (Fig. 2E). Our assumption that perlb is expressed in the PT region is also based on our antibody-staining result of TH and PER1 colocalization in the SN/VTA DA neurons in mice (Fig. $2 H$ ). Even though zebrafish Perlb is not expressed in the PT region, it may still play an indirect role in the PT region.

Recent GWAS suggest that ADHD is polygenic (Franke et al., 2012), and implicate circadian genes, particularly PER1, as possible ADHD-susceptible genes (Lasky-Su et al., 2008; Xu et al., 2010). First of all, our work shows how zebrafish research can be useful for evaluating human GWAS. For example, we show that among single nucleotide polymorphism in the human PER1 locus is among the many genes associated with ADHD, along with many other genes (Lasky-Su et al., 2008). In addition, however, our work shows a causative relationship and provides a mechanism for the association.

Previous studies have already revealed that canonical circadian clock genes play important roles in cognitive and psychiatric behaviors (Karatsoreos, 2014). For instance, both Bmall and Period2 knock-out mice display mania-like behavior (McClung, 2013), while Cry1 and Cry2 double-knock-out mice exhibit cognitive dysfunction and elevated anxiety (De Bundel et al., 2013). In particular, both Clock and Rev-erb $\alpha$ can regulate $\mathrm{TH}$, the ratelimiting enzyme in the biosynthesis of DA and other catecholamines, and mice lacking either Clock or Rev-erb $\alpha$ display elevated midbrain dopaminergic activities and mania-like behavior (Roybal et al., 2007; Chung et al., 2014). Here, our study found that the circadian clock directly controls mao and $d b h$, which are involved in DA catabolism and the conversion of DA into NE, respectively. Transcription of these two genes are activated by the Clock:Bmal heterodimer but repressed by Per1b, and loss of Perlb function leads to mao and $d b h$ upregulation, which may in turn result in DA reduction and thus contribute to ADHD (Fig. 9E). While the circadian control of MaoA (an ortholog of zebrafish mao) transcription was reported previously in mouse (Hampp et al., 2008), our study is the first to show direct regulation of $d b h$ by the circadian clock.

Even though ADHD has long been regarded as a neurodevelopmental disorder, the underlying mechanism remains largely unknown (Lange et al., 2012). Our study suggests a mechanism for the impaired development of dopaminergic neurons in $\mathrm{ADHD}$, as well as regulatory roles of Per1b on genes essential for development or maintenance of dopaminergic neurons. In zebrafish per $1 b$ mutants, otpa, otpb, wnt $1, w n t 3 a, w n t 5 a$, and manf, which are critical for specification, differentiation, development, or maintenance of dopaminergic neurons, were all downregulated. Downregulation of these genes could lead to the observed partial loss and disorganization of dopaminergic neurons in the per $1 b$ mutant diencephalic PT. Impairment of dopaminergic neuron development also should lead to DA reduction and ADHD-like symptoms (Fig. 9E).

In summary, Per $1 \mathrm{~b}$ is required to prevent ADHD-like symptoms in zebrafish and appears to work by regulating endogenous DA levels in two ways (Fig. 9E): first, by acting through DArelated enzymes, transporters, and receptors to directly regulate the endogenous DA level, and second, by acting through genes critical for specification, differentiation, development, or maintenance of dopaminergic neurons to possibly regulate the number and spatial organization of dopaminergic neurons (Fig. 9E). Zebrafish possesses two orthologs of the mammalian Perl gene, perla and per $1 b$. These were derived from the teleost genome duplication, which occurred $\sim 300$ million years ago (Amores et al., 1998; Postlethwait and Braasch, 2012). The role of Perla in $\mathrm{ADHD}$ remains to be investigated. However, our previous study showed that perla has a rather more specific expression pattern than per $1 b$, and has evolved distinct molecular mechanisms underlying temporal and spatial expression (Wang, 2008), which suggests that per $1 a$ either plays a compensatory role for per $1 b$ or has a different function from per $1 b$. Nevertheless, our per $1 b \mathrm{mu}-$ tant provides not only new insights into the pathogenesis of ADHD, but importantly, identifies Perl as a new therapeutic tar- 
get for ADHD diagnosis and treatment. Unlike many rodent models for ADHD (Yamada, 2011), per1b mutant zebrafish have normal body weight and body length, and show no signs of obvious physiological or metabolic defects. The fact that per $1 b \mathrm{mu}-$ tant fish contain lower levels of DA than wild types makes them a particularly good subject for studying mechanisms underlying hypodopaminergic ADHD and behaviors. Because zebrafish are readily suitable for large-scale and high-throughput drug discovery (Lieschke and Currie, 2007), this zebrafish perlb mutant should be invaluable in identifying new drugs for potential treatments of the neuropsychiatric disorders associated with the alteration of the brain dopaminergic system, such as ADHD, Parkinson's disease, and addiction (Hollander and Stein, 2006).

\section{References}

Akhondzadeh S, Tavakolian R, Davari-Ashtiani R, Arabgol F, Amini H (2003) Selegiline in the treatment of attention deficit hyperactivity disorder in children: a double blind and randomized trial. Prog Neuropsychopharmacol Biol Psychiatry 27:841-845. CrossRef Medline

Alsop B (2007) Problems with spontaneously hypertensive rats (SHR) as a model of attention-deficit/hyperactivity disorder (AD/HD). J Neurosci Methods 162:42-48. CrossRef Medline

Amores A, Force A, Yan YL, Joly L, Amemiya C, Fritz A, Ho RK, Langeland J, Prince V, Wang YL, Westerfield M, Ekker M, Postlethwait JH (1998) Zebrafish hox clusters and vertebrate genome evolution. Science 282: 1711-1714. CrossRef Medline

Appelbaum L, Wang G, Yokogawa T, Skariah GM, Smith SJ, Mourrain P, Mignot E (2010) Circadian and homeostatic regulation of structural synaptic plasticity in hypocretin neurons. Neuron 68:87-98. CrossRef Medline

Arcos-Burgos M, Jain M, Acosta MT, Shively S, Stanescu H, Wallis D, Domené S, Vélez JI, Karkera JD, Balog J, Berg K, Kleta R, Gahl WA, Roessler E, Long R, Lie J, Pineda D, Londoño AC, Palacio JD, Arbelaez A, et al. (2010) A common variant of the latrophilin 3 gene, LPHN3, confers susceptibility to ADHD and predicts effectiveness of stimulant medication. Mol Psychiatry 15:1053-1066. CrossRef Medline

Bae K, Jin X, Maywood ES, Hastings MH, Reppert SM, Weaver DR (2001) Differential functions of mPer 1, mPer2, and mPer3 in the SCN circadian clock. Neuron 30:525-536. CrossRef Medline

Baird AL, Coogan AN, Siddiqui A, Donev RM, Thome J (2012) Adult attention-deficit hyperactivity disorder is associated with alterations in circadian rhythms at the behavioural, endocrine and molecular levels. Mol Psychiatry 17:988-995. CrossRef Medline

Ben-Moshe Z, Alon S, Mracek P, Faigenbloom L, Tovin A, Vatine GD, Eisenberg E, Foulkes NS, Gothilf Y (2014) The light-induced transcriptome of the zebrafish pineal gland reveals complex regulation of the circadian clockwork by light. Nucleic Acids Res 42:3750-3767. CrossRef Medline

Bolyard KJ, Rowland WJ (1996) Context-dependent response to red coloration in stickleback. Anim Behav 52:5.

Bruno KJ, Freet CS, Twining RC, Egami K, Grigson PS, Hess EJ (2007) Abnormal latent inhibition and impulsivity in coloboma mice, a model of ADHD. Neurobiol Dis 25:206-216. CrossRef Medline

Castelo-Branco G, Wagner J, Rodriguez FJ, Kele J, Sousa K, Rawal N, Pasolli HA, Fuchs E, Kitajewski J, Arenas E (2003) Differential regulation of midbrain dopaminergic neuron development by Wnt-1, Wnt-3a, and Wnt-5a. Proc Natl Acad Sci U S A 100:12747-12752. CrossRef Medline

Cermakian N, Monaco L, Pando MP, Dierich A, Sassone-Corsi P (2001) Altered behavioral rhythms and clock gene expression in mice with a targeted mutation in the Period1 gene. EMBO J 20:3967-3974. CrossRef Medline

Chen YC, Sundvik M, Rozov S, Priyadarshini M, Panula P (2012) MANF regulates dopaminergic neuron development in larval zebrafish. Dev Biol 370:237-249. CrossRef Medline

Cheon KA, Ryu YH, Kim YK, Namkoong K, Kim CH, Lee JD (2003) Dopamine transporter density in the basal ganglia assessed with [123I]IPT SPET in children with attention deficit hyperactivity disorder. Eur J Nucl Med Mol Imaging 30:306-311. CrossRef Medline

Cho H, Zhao X, Hatori M, Yu RT, Barish GD, Lam MT, Chong LW, DiTacchio L, Atkins AR, Glass CK, Liddle C, Auwerx J, Downes M, Panda S, Evans RM (2012) Regulation of circadian behaviour and metabolism by
REV-ERB-alpha and REV-ERB-beta. Nature 485:123-127. CrossRef Medline

Chung S, Lee EJ, Yun S, Choe HK, Park SB, Son HJ, Kim KS, Dluzen DE, Lee I, Hwang O, Son GH, Kim K (2014) Impact of circadian nuclear receptor REV-ERBalpha on midbrain dopamine production and mood regulation. Cell 157:858-868. CrossRef Medline

De Bundel D, Gangarossa G, Biever A, Bonnefont X, Valjent E (2013) Cognitive dysfunction, elevated anxiety, and reduced cocaine response in circadian clock-deficient cryptochrome knockout mice. Front Behav Neurosci 7:152. CrossRef Medline

Dijk DJ, von Schantz M (2005) Timing and consolidation of human sleep, wakefulness, and performance by a symphony of oscillators. J Biol Rhythms 20:279-290. CrossRef Medline

Dougherty DD, Bonab AA, Spencer TJ, Rauch SL, Madras BK, Fischman AJ (1999) Dopamine transporter density in patients with attention deficit hyperactivity disorder. Lancet 354:2132-2133. CrossRef Medline

Ezcurra M, Tanizawa Y, Swoboda P, Schafer WR (2011) Food sensitizes C. elegans avoidance behaviours through acute dopamine signalling. EMBO J 30:1110-1122. CrossRef Medline

Franke B, Faraone SV, Asherson P, Buitelaar J, Bau CH, Ramos-Quiroga JA, Mick E, Grevet EH, Johansson S, Haavik J, Lesch KP, Cormand B, Reif A, Reif A (2012) The genetics of attention deficit/hyperactivity disorder in adults, a review. Mol Psychiatry 17:960-987. CrossRef Medline

Geissler J, Lesch KP (2011) A lifetime of attention-deficit/hyperactivity disorder: diagnostic challenges, treatment and neurobiological mechanisms. Expert Rev Neurother 11:1467-1484. CrossRef Medline

Glaser PEA, Gerhardt GA (2012) The neuropsychopharmacology of stimulants: dopamine and ADHD. In: current directions in ADHD and its treatment (Norvilitis JM, ed). Rijeka, Croatia: InTech.

Golling G, Amsterdam A, Sun Z, Antonelli M, Maldonado E, Chen W, Burgess S, Haldi M, Artzt K, Farrington S, Lin SY, Nissen RM, Hopkins N (2002) Insertional mutagenesis in zebrafish rapidly identifies genes essential for early vertebrate development. Nat Genet 31:135-140. CrossRef Medline

Gong R, Ding C, Hu J, Lu Y, Liu F, Mann E, Xu F, Cohen MB, Luo M (2011) Role for the membrane receptor guanylyl cyclase-C in attention deficiency and hyperactive behavior. Science 333:1642-1646. CrossRef Medline

Gunn RK, Huentelman MJ, Brown RE (2011) Are Sema5a mutant mice a good model of autism? A behavioral analysis of sensory systems, emotionality and cognition. Behav Brain Res 225:142-150. CrossRef Medline

Hampp G, Ripperger JA, Houben T, Schmutz I, Blex C, Perreau-Lenz S, Brunk I, Spanagel R, Ahnert-Hilger G, Meijer JH, Albrecht U (2008) Regulation of monoamine oxidase A by circadian-clock components implies clock influence on mood. Curr Biol 18:678-683. CrossRef Medline

Harbers K, Kuehn M, Delius H, Jaenisch R (1984) Insertion of retrovirus into the first intron of alpha $1(\mathrm{I})$ collagen gene to embryonic lethal mutation in mice. Proc Natl Acad Sci U S A 81:1504-1508. CrossRef Medline

Hess EJ, Jinnah HA, Kozak CA, Wilson MC (1992) Spontaneous locomotor hyperactivity in a mouse mutant with a deletion including the Snap gene on chromosome 2. J Neurosci 12:2865-2874. Medline

Hess EJ, Collins KA, Wilson MC (1996) Mouse model of hyperkinesis implicates SNAP-25 in behavioral regulation. J Neurosci 16:3104-3111. Medline

Hollander E, Stein DJ (2006) Clinical manual of impulse-control disorders, 1st Edition. Arlington, VA: American Psychiatric Publishing.

Howard GC, Kaser MR (2007) Making and using antibodies: a practical handbook. Boca Raton, FL: CRC/Taylor and Francis.

Hurd MW, Debruyne J, Straume M, Cahill GM (1998) Circadian rhythms of locomotor activity in zebrafish. Physiol Behav 65:465-472. CrossRef Medline

Jones MD, Hess EJ (2003) Norepinephrine regulates locomotor hyperactivity in the mouse mutant coloboma. Pharmacol Biochem Behav 75:209216. CrossRef Medline

Karatsoreos IN (2014) Links between circadian rhythms and psychiatric disease. Front Behav Neurosci 8:162. CrossRef Medline

Kendall T, Taylor E, Perez A, Taylor C, Guideline Development G (2008) Diagnosis and management of attention-deficit/hyperactivity disorder in children, young people, and adults: summary of NICE guidance. BMJ 337:a1239. CrossRef Medline

Kobayashi Y, Ishikawa T, Hirayama J, Daiyasu H, Kanai S, Toh H, Fukuda I, Tsujimura T, Terada N, Kamei Y, Yuba S, Iwai S, Todo T (2000) Molec- 
ular analysis of zebrafish photolyase/cryptochrome family: two types of cryptochromes present in zebrafish. Genes Cells 5:725-738. CrossRef Medline

Lange M, Norton W, Coolen M, Chaminade M, Merker S, Proft F, Schmitt A, Vernier P, Lesch KP, Bally-Cuif L (2012) The ADHD-susceptibility gene lphn3.1 modulates dopaminergic neuron formation and locomotor activity during zebrafish development. Mol Psychiatry 17:946-954. CrossRef Medline

Lasky-Su J, Neale BM, Franke B, Anney RJ, Zhou K, Maller JB, Vasquez AA, Chen W, Asherson P, Buitelaar J, Banaschewski T, Ebstein R, Gill M, Miranda A, Mulas F, Oades RD, Roeyers H, Rothenberger A, Sergeant J, Sonuga-Barke E, et al. (2008) Genome-wide association scan of quantitative traits for attention deficit hyperactivity disorder identifies novel associations and confirms candidate gene associations. Am J Med Genet B Neuropsychiatr Genet 147B:1345-1354. CrossRef Medline

Lieschke GJ, Currie PD (2007) Animal models of human disease: zebrafish swim into view. Nat Rev Genet 8:353-367. CrossRef Medline

Liu Z, Huang M, Wu X, Shi G, Xing L, Dong Z, Qu Z, Yan J, Yang L, Panda S, Xu Y (2014) PER1 phosphorylation specifies feeding rhythm in mice. Cell Rep 7:1509-1520. CrossRef Medline

Lou HC, Rosa P, Pryds O, Karrebaek H, Lunding J, Cumming P, Gjedde A (2004) ADHD: increased dopamine receptor availability linked to attention deficit and low neonatal cerebral blood flow. Dev Med Child Neurol 46:179-183. Medline

Luo AH, Tahsili-Fahadan P, Wise RA, Lupica CR, Aston-Jones G (2011) Linking context with reward: a functional circuit from hippocampal CA3 to ventral tegmental area. Science 333:353-357. CrossRef Medline

McClung CA (2013) How might circadian rhythms control mood? Let me count the ways. Biol Psychiatry 74:242-249. CrossRef Medline

McClung CA, Sidiropoulou K, Vitaterna M, Takahashi JS, White FJ, Cooper DC, Nestler EJ (2005) Regulation of dopaminergic transmission and cocaine reward by the Clock gene. Proc Natl Acad Sci U S A 102:9377-9381. CrossRef Medline

Nestler EJ, Hyman SE, Malenka RC (2009) Molecular neuropharmacology: a foundation for clinical neuroscience, 2nd edition. New York: McGrawHill Medical.

Parker MO, Millington ME, Combe FJ, Brennan CH (2012) Development and implementation of a three-choice serial reaction time task for zebrafish (Danio rerio). Behav Brain Res 227:73-80. CrossRef Medline

Pastor PN, Reuben CA, National Health Interview Survey (U.S.), National Center for Health Statistics (U.S.) (2008) Diagnosed attention deficit hyperactivity disorder and learning disability, United States, 2004-2006: data from the National Health Interview Survey. Hyattsville, MD: U.S. Dept. of Health and Human Services, Centers for Disease Control and Prevention, National Center for Health Statistics.

Pendergast JS, Niswender KD, Yamazaki S (2012) Tissue-specific function of Period3 in circadian rhythmicity. PLoS One 7:e30254. CrossRef Medline

Philipsen A, Hornyak M, Riemann D (2006) Sleep and sleep disorders in adults with attention deficit/hyperactivity disorder. Sleep Med Rev 10: 399-405. CrossRef Medline

Postlethwait JH, Braasch I (2012) Polyploidy in fish and the teleost genome duplication. In: Polyploidy and genome evolution (Soltis P, Soltis DE, eds), pp 341-383. New York: Springer Heidelberg.

Prober DA, Rihel J, Onah AA, Sung RJ, Schier AF (2006) Hypocretin/orexin overexpression induces an insomnia-like phenotype in zebrafish. J Neurosci 26:13400-13410. CrossRef Medline

Rawashdeh O, de Borsetti NH, Roman G, Cahill GM (2007) Melatonin suppresses nighttime memory formation in zebrafish. Science 318:11441146. CrossRef Medline
Rihel J, Prober DA, Arvanites A, Lam K, Zimmerman S, Jang S, Haggarty SJ, Kokel D, Rubin LL, Peterson RT, Schier AF (2010) Zebrafish behavioral profiling links drugs to biological targets and rest/wake regulation. Science 327:348-351. CrossRef Medline

Rink E, Wullimann MF (2002) Development of the catecholaminergic system in the early zebrafish brain: an immunohistochemical study. Brain Res Dev Brain Res 137:89-100. CrossRef Medline

Rösler M, Retz W, Retz-Junginger P, Hengesch G, Schneider M, Supprian T, Schwitzgebel P, Pinhard K, Dovi-Akue N, Wender P, Thome J (2004) Prevalence of attention deficit-/hyperactivity disorder (ADHD) and comorbid disorders in young male prison inmates. Eur Arch Psychiatry Clin Neurosci 254:365-371. CrossRef Medline

Roybal K, Theobold D, Graham A, DiNieri JA, Russo SJ, Krishnan V, Chakravarty S, Peevey J, Oehrlein N, Birnbaum S, Vitaterna MH, Orsulak P, Takahashi JS, Nestler EJ, Carlezon WA Jr, McClung CA (2007) Manialike behavior induced by disruption of CLOCK. Proc Natl Acad Sci U S A 104:6406-6411. CrossRef Medline

Ryu S, Mahler J, Acampora D, Holzschuh J, Erhardt S, Omodei D, Simeone A, Driever W (2007) Orthopedia homeodomain protein is essential for diencephalic dopaminergic neuron development. Curr Biol 17:873-880. CrossRef Medline

Tay TL, Ronneberger O, Ryu S, Nitschke R, Driever W (2011) Comprehensive catecholaminergic projectome analysis reveals single-neuron integration of zebrafish ascending and descending dopaminergic systems. Nat Commun 2:171. CrossRef Medline

Toh KL, Jones CR, He Y, Eide EJ, Hinz WA, Virshup DM, Ptácek LJ, Fu YH (2001) An hPer2 phosphorylation site mutation in familial advanced sleep phase syndrome. Science 291:1040-1043. CrossRef Medline

Tovin A, Alon S, Ben-Moshe Z, Mracek P, Vatine G, Foulkes NS, JacobHirsch J, Rechavi G, Toyama R, Coon SL, Klein DC, Eisenberg E, Gothilf Y (2012) Systematic identification of rhythmic genes reveals camklgb as a new element in the circadian clockwork. PLoS Genet 8:e1003116. CrossRef Medline

Vallone D, Gondi SB, Whitmore D, Foulkes NS (2004) E-box function in a period gene repressed by light. Proc Natl Acad Sci U S A 101:4106-4111. CrossRef Medline

VanGuilder HD, Vrana KE, Freeman WM (2008) Twenty-five years of quantitative PCR for gene expression analysis. Biotechniques 44:619626. Medline

Wang H (2008) Comparative analysis of period genes in teleost fish genomes. J Mol Evol 67:29-40. CrossRef Medline

Wang H, Zhou Q, Kesinger JW, Norris C, Valdez C (2007) Heme regulates exocrine peptidase precursor genes in zebrafish. Exp Biol Med (Maywood) 232:1170-1180. CrossRef Medline

Wang L, Zhang P, Wei Y, Gao Y, Patient R, Liu F (2011) A blood flowdependent klf2a-NO signaling cascade is required for stabilization of hematopoietic stem cell programming in zebrafish embryos. Blood 118: 4102-4110. CrossRef Medline

Westerfield M (1993) The zebrafish book: a guide for the laboratory use of zebrafish (Brachydanio rerio). Eugene, OR: University of Oregon.

Xu X, Breen G, Chen CK, Huang YS, Wu YY, Asherson P (2010) Association study between a polymorphism at the 3 '-untranslated region of CLOCK gene and attention deficit hyperactivity disorder. Behav Brain Funct 6:48. CrossRef Medline

Yamada K (2011) Translational research in neurodevelopmental disorders: development of etiology-based animal models. Forward. Biol Pharm Bull 34:1357. CrossRef Medline

Zhu J, Lee KP, Spencer TJ, Biederman J, Bhide PG (2014) Transgenerational transmission of hyperactivity in a mouse model of ADHD. J Neurosci 34:2768-2773. CrossRef Medline 